\title{
Competition and Incentives with Motivated Agents
}

Timothy Besley and Maitreesh Ghatak

London School of Economics and Political Science

Contents:

Abstract

1. Introduction

2. The Model

3. Analysis

4. Applications

5. Concluding Remarks

References

Appendix A: Proofs

Appendix B: Sorting on Motivation

Discussion Paper

No.TE/03/465

November 2003
The Suntory Centre

Suntory and Toyota International Centres for Economics and Related Disciplines

London School of Economics and Political Science Houghton Street

London WC2A 2AE

Tel.: 020-7955 6698

* The authors would like to thank Leonardo Felli and Meg Meyer for useful discussions, Daron Acemoglu, Alberto Alesina, Michela Cella, Julian Le Grand, Daniel Sturm and Jean Tirole for helpful comments, and a number of seminar audiences for helpful feedback. 


\section{Abstract}

A unifying theme in the literature on organizations such as public bureaucracies and private non-profits is the importance of missions, as opposed to profit, as an organizational goal. Such mission-oriented organizations are frequently staffed by motivated agents who subscribe to the mission. This paper studies incentives in such contexts and emphazises the role of matching principals' and agents' mission preferences in increasing organizational efficiency. Matching economizes on the need for high-powered incentives. However, it can also entrench bureaucratic conservatism and resistance to innovations. The framework developed in this paper is applied to school competition, incentives in the public sector and in private nonprofits, and the interdependence of incentives and productivity between the private for-profit sector and the mission-oriented sector through occupational choice.

Keywords: Motivated agents; incentives in the public sector; school competition. JEL Nos.: D21, D23, H41, J41, L22, L31, L33.

(C) by the authors. All rights reserved. Short sections of text, not to exceed two paragraphs, may be quoted without explicit permission, provided that full credit, including (c) notice, is given to the source.

Contact addresses:

Professor Timothy Besley, STICERD, London School of Economics and Political Science, Houghton Street, London WC2A 2AE, UK. Email. t.besley@Ise.ac.uk

Dr Maitreesh Ghatak, STICERD, London School of Economics and Political Science, Houghton Street, London WC2A 2AE, UK. Email: m.ghatak@Ise.ac.uk 


\section{Introduction}

The late twentieth century witnessed an historic high in the march of market capitalism with unbridled optimism in the role of the profit motive in promoting welfare in the production of private goods. Moreover, this generated a broad consensus on the optimal organization of profit-oriented production through privately-owned competitive firms. When it comes to the provision of collective goods, no such consensus has emerged. ${ }^{1}$ Debates about the relative merits of public and private provision still dominate.

This paper suggests a contracting approach to the provision of collective goods which cuts across the traditional public-private divide. It focuses on two key issues: (i) how to structure incentives and (ii) the role of competition between providers. At its heart is the idea that organizations for the provision of collective goods cohere around a mission. ${ }^{2}$ Thus production of collective goods can be viewed as mission-oriented.

Not all activities within the public-sector are mission-oriented. For example, in some countries, governments own car plants. While this is part of the public-sector, the optimal organization design issues here are no different than those faced by GM or Ford. Not all private sector activity is profit-oriented. Universities, whether public or private, have many goals at variance with profit maximization.

The missions pursued in the provision of collective goods come from the underlying motivations of the individuals (principals and agents) who work in the mission-oriented sector. Workers are typically motivated agents, i.e. agents who pursue goals because they perceive intrinsic benefits from doing so. There are many examples - doctors who are committed to saving lives, researchers to advancing knowledge, judges to promoting justice and soldiers to defending their country in battle. Viewing workers as mission-oriented makes sense when the output of the mission-oriented sector is thought of as producing collective goods. The benefits and costs generated by mission-oriented production organizations are typically not priced. In addition, donating one's income earned in the market is likely to be an imperfect substitute to

\footnotetext{
${ }^{1}$ We use the term collective good as opposed to the stricter notion of a public good. Collective goods in this sense also include merit goods. This label also includes a good like education to which there is a commitment to collective provision even though the returns are mainly private.

${ }^{2}$ See, for example, Wilson (1989) on public bureaucracies and Sheehan (1998) on non-profits. Tirole (1994) is the first paper to explore the implications of these ideas for incentive theory.
} 
joining and working in such an organization in the presence of agency costs or because individuals care not just about the levels of these collective goods, but their personal involvement in their production (i.e., a "warm glow").

The possibility of worker motivation economizes on the need for explicit monetary incentives while accentuating the importance of non-pecuniary aspects of organization design in increasing effort. Thus, mission choice can affect the productivity of the organization. For example, a school curriculum or method of discipline that is agreed to by the whole teaching faculty can raise school productivity.

However, mission preferences typically differ between motivated agents. Doctors may have different views about the right way to treat ill patients and teachers may prefer to teach to different curriculums. This suggests a role for organizational diversity in promoting alternative missions and competition between organizations in attracting those whose motivational preferences best fit with one another. We show that there is direct link between such sorting and an organization's productivity.

The insights from the approach have applications to a wide variety of organizations including schools, hospitals, universities and armies. The primitives are not whether the organization is publicly or privately owned but the production technology, the motivations of the actors and the competitive environment. We also abstract (for the most part) from issues of financing.

We benchmark the behavior of the mission-oriented part of the economy against a profitoriented sector where standard economic assumptions are made - profit seeking and no nonpecuniary agent motivation. This is important for two reasons. First, we get a precise contrast between the incentive structures of profit-oriented and mission-oriented production. Second, the analysis casts light on how changes in private sector productivity affect optimal incentive schemes operating in the mission-oriented sector. This has implications for debates about how pay-setting in public sector bureaucracies responds to the private sector.

Our approach yields useful insights into on-going debates about the organization of the mission-oriented sector of the economy. For example, it offers new insights into the role of competition in enhancing productivity in schools. More generally, it suggests that one of the potential virtues of private non-profit activity is that it can generate a variety of different missions which improve productivity by matching managers and workers who have similar mission preferences. An analogous argument can be made in support of decentralization of 
public services. However, on the flip side, public bureaucracies, whose policies can be imposed by politicians, may easily become de-motivated. While matching on mission preferences is potentially productivity enhancing, it also leads to conservatism and can raise the cost of organizational change.

This paper contributes to an emerging literature which studies incentive issues outside of the standard private goods model. ${ }^{3}$ One strand of this puts weight on the multi-tasking aspects of non-profit and government production along the lines of Holmstrom and Milgrom (1991). Another emphasizes the career concerns aspects of bureaucracies (Dewatripont, Jewitt and Tirole (1999), Alesina and Tabellini (2003)). These two are brought together in Acemoglu, Kremer and Mian (2003). However, these all work with standard motivational assumptions. This paper shares in common with Akerlof and Kranton (2003), Benabou and Tirole (2003), Dixit (2001), Francois (2000), Murdock (2002), and Seabright (2003) the notion that nonpecuniary aspects of motivation matter. ${ }^{4}$ In common with Crawford and Sobel (1982) and Aghion and Tirole (1997) our approach places emphasizes how non-congruence in organizational objectives can play a role in incentive design. However, we explore the role of matching principals and agents - selection rather than incentives - as a way to overcome this. ${ }^{5}$

The remainder of the paper is organized as follows. In the next section, we lay out the basic model. Section three studies optimal contracts and competition to match principals and agents. Section four explores applications of the model and section five concludes.

\section{The Model}

\subsection{The Environment}

A "firm" consists of a risk neutral principal and an agent who is needed to carry out a project. The project's outcome (which can be interpreted as quality) can be high or low: $Y_{H}=1$ ('high' or 'success') and $Y_{L}=0$ ('low' or 'failure'). The probability of the high outcome is the effort supplied by the agent, $e$, at a cost $c(e)=e^{2} / 2$. Effort is unobservable and hence non-

\footnotetext{
${ }^{3}$ See Dixit (2002) for a survey of this literature.

${ }^{4}$ Some of these ideas consider the possibility that intrinsic motivation can be affected by the use of explicit incentives (see also Titmuss (1970), Frey (1997)). We treat the level of intrinsic motivation as given.

${ }^{5}$ See Ackerberg and Botticini (2002), Dam and Perez-Castrillo (2001), and Lazear (2000) for approaches to principal agent problems where sorting is important.
} 
contractible. We assume that the agent has no wealth which can be used as a performance bond in the event of poor performance. Thus, a limited liability constraint operates which implies that the agent has to be given a minimum consumption level of $\underline{w} \geq 0$ every period. Because of the limited-liability constraint, the moral hazard problem has bite. This is the only departure from the first-best in our model.

We assume that each principal has sufficient wealth so as not to face any binding wealth constraints, and that the principal and agent can obtain an autarchy payoff of zero.

There are two sectors in the economy. A profit-oriented sector produces a good or service that does not generate non-pecuniary benefits to those who work in it - for example, investment banking. A mission-oriented sector produces a good or service that may generate non-pecuniary benefits to the principals and agents who produce it - for example, education. The sets of types of principals and agents are denoted by $\mathcal{A}_{p}$ and $\mathcal{A}_{a}$ with typical elements $p_{k}$ and $a_{j}$. Each has cardinality $M+1$, i.e., there are $M+1$ types of principals and agents. Of these the types $1, \ldots, M$ are motivated. They receive some non-pecuniary benefits if they work in the mission-oriented sector. Type $M+1$ denotes unmotivated principals or agents. They have the standard principal-agent preferences. A principal has some special skill that makes him productive in any one of the two sectors only. In particular, motivated principals (types $1,2, . ., M)$ are productive in the mission-oriented sector and unmotivated principals (type $M+1$ ) are productive in the profit-oriented sector. However, each type of agent is equally productive in both sectors - the only difference is in the size of the non-pecuniary benefit that they derive from working in the mission-oriented sector. ${ }^{6}$ The types of principals and agents are fully observed.

If an agent of type $a_{j}(j=1,2, . ., M, M+1)$ matches with a principal of type $p_{k}(k=$ $1,2, . ., M, M+1$ ), then if the project is a success they receive a (pre-contractual) payoff of $\theta_{j k}^{a}$ and $\theta_{k j}^{p}$ respectively. The principal and the agent receive a payoff of zero if the project fails.

If a motivated agent of type $a_{j}(j=1,2, . ., M)$ matches with a motivated principal of type $p_{k}(k=1,2, . ., M)$, these payoffs from success depend on $x \in \Re$, which is the "mission" of the organization and will be denoted by $\theta_{j k}^{a}(x)$ and $\theta_{k j}^{p}(x)$ in this case. The mission $x$ is chosen by

\footnotetext{
${ }^{6}$ This is a simplifying assumption. We can allow each type of principal to work in either one of the two sectors without affecting the main results qualitatively. In that case their equilibrium occupational choice would depend on the extent of the non-pecuniary benefits they receive in the mission-oriented sector, and the supply of agents of different types.
} 
the principal and is contractible, i.e., the principal can commit to it at the time of signing the contract. We will work with the following simple form of preferences for motivated principals and agents when they match with one another:

$$
\begin{aligned}
& \theta_{k j}^{p}(x)=\omega_{p}\left\{1-\frac{1}{2}\left(\alpha_{k}-x\right)^{2}\right\} \\
& \theta_{j k}^{a}(x)=\omega_{a}\left\{1-\frac{1}{2}\left(\alpha_{j}-x\right)^{2}\right\}
\end{aligned}
$$

for $k=1,2, . ., M$ and $j=1,2, . ., M$, where $\alpha_{k}, \alpha_{j} \in[\underline{\alpha}, \bar{\alpha}]$ with $0 \leq \underline{\alpha}<\bar{\alpha}, \omega_{a} \geq 0$, and $\omega_{p}>0 .^{7}$ Each motivated principal and agent has an ideal mission as represented by $\alpha$. Let $\bar{\Delta}=\bar{\alpha}-\underline{\alpha}$ be a measure of mission preference diversity in the whole population. The agent's payoff if he is matched with a motivated principal is entirely non-pecuniary. ${ }^{8}$ However, the principal's payoff could arise (partially or wholly) from selling the output in the market. We make:

\section{Assumption 1:}

$$
\omega_{a}+\omega_{p}<1 \text { and } \bar{\Delta}^{2}<2 .
$$

These ensure that $\theta_{k j}^{p}(x)>0, \theta_{j k}^{a}(x)>0$ for $x$ between $\bar{\alpha}$ and $\underline{\alpha}$ and $\theta_{k j}^{p}(x)+\theta_{j k}^{a}(x)<1$, which we will see later, ensures an interior solution for effort in the mission-oriented sector.

An unmotivated principal (type $p_{M+1}$ ) receives a monetary payoff:

$$
\theta_{M+1 j}^{p}=\pi \text { for all } j=1,2, . ., M, M+1
$$

from operating in the profit-oriented sector if the project is successful irrespective to the type of the agent he is matched with. If a motivated principal (type $p_{k}, k=1,2, . ., M$ ) is matched with an unmotivated agent (type $a_{M+1}$ ), for a given value of $x$ his payoff is the same as what he would receive if he was matched with a motivated agent, as given by (1). This reflects the assumption that there is no difference in the abilities of different types of agents, whether they work in the profit-oriented sector or the mission-oriented sector.

An unmotivated agent receives no non-pecuniary payoff, i.e., $\theta_{M+1 j}^{a}(x)=0$ for all $j=$ $1,2, . ., M+1$ irrespective of which principal he is matched with. If a motivated agent works in

\footnotetext{
${ }^{7}$ Thus, in this case $p_{k}=\alpha_{k}$ and $a_{j}=\alpha_{j}$ for $j, k=1, \ldots, M$.

${ }^{8}$ These payoffs are contractible, unlike in Hart and Holmstrom (2002) where non-contractibility of private benefits plays an important role. Also, these are independent of monetary incentives, which is contrary to the assumption in the behavioral economics literature (see Frey, 1997).
} 
the profit-oriented sector (or, equivalently, for an unmotivated principal) then he too receives no non-pecuniary payoff, i.e.,

$$
\theta_{j M+1}^{a}(x)=0 \text { for } j=1,2, . ., M \text {. }
$$

The population of types $1, \ldots, M$ is assumed to be balanced in the sense that there are equal numbers of every type in the population. Let $n_{m}^{\ell}(\ell \in\{a, p\})$ be the number of principals and agents of each type. We assume that $n_{m}^{a}=n_{m}^{p}$ for all $m \leq M$, i.e., the population of motivated principals and agents is balanced. However, in the unmotivated sector we allow for both unemployment, i.e., $n_{M+1}^{a}>n_{M+1}^{p}$, and full employment, i.e., $n_{M+1}^{a}<n_{M+1}^{p}$.

We assume that $\pi$ is high enough so that unmotivated principals can generate positive surplus despite the presence of moral hazard:

\section{Assumption 2:}

$$
\frac{1}{4} \pi^{2}-\underline{w}>0
$$

An analogous assumption is made regarding the mission-oriented sector:

\section{Assumption 3:}

$$
\begin{aligned}
\frac{1}{2} \omega_{a} \omega_{p} & >\underline{w} \text { for all } \omega_{a}>\omega_{p} \\
\frac{1}{8}\left(\omega_{a}+\omega_{p}\right)^{2} & >\underline{w} \text { for all } \omega_{a} \leq \omega_{p} .
\end{aligned}
$$

These conditions are satisfied for high values of $\omega_{a}$ and/or $\omega_{p}$ and low values of $\underline{w}$.

When the mission-oriented and profit-oriented sectors compete for agents, our final assumption ensures that mission-oriented production is viable ${ }^{9}$ :

\section{Assumption 4:}

$$
\omega_{a}+\omega_{p} \geq \pi
$$

Discussion: In our formulation, the payoffs $\theta_{k j}^{p}$ and $\theta_{j k}^{a}$ of motivated principals and agents (so long a motivated agent is not matched with an unmotivated principal) depend on two

\footnotetext{
${ }^{9}$ Combined with Assumption 1, this assumption also guarantees an interior solution for effort in the profitoriented sector.
} 
sets of taste-parameters. These relate to motivation $\left(\omega_{p}\right.$ and $\left.\omega_{a}\right)$ and mission-preference $\left(\alpha_{k}\right.$ and $\alpha_{j}$ ). Motivation is a measure of warm-glow: for example, how much the principal or the agent cares about successfully running a school or a patient's health. The deviation of actual mission choice from their preferred mission choice however dampens the motivations of the principal and the agent to some degree. For example, the principal might prefer an emphasis on religion in the syllabus, whereas the teacher might prefer an emphasis on science. In this set up missions are rather like ideologies - there is an underlying conflict in the preferences of different types about how the organization should be oriented.

A "mission" consists of attributes of a project that make people value its success over and above any monetary income they receive in the process. As mentioned earlier, these attributes are assumed to have missing markets, and in addition, this non-monetary valuation is contingent on the direct participation of the principal and the agent. In our theoretical model we make no distinction between the "private" (or for-profit) and "public" (or non-profit) sectors as both could have firms that have mission-driven managers and workers. However, most of our applications are from the public sector and the private non-profit sector.

Take the example of a school. The principal is a school principal (head teacher) with responsibility for running a school. The agent is the teacher whom he employs. The project is the performance of the students. If there is a market for education, then $e \theta_{k j}^{p}$ may in part reflect the expected revenue of the principal by providing high quality education. Some of the teachers are partly motivated towards educational success. The mission of the organization is the teaching curriculum (which can vary in terms of, say, the importance of religion). The teachers have the ability to work in the financial sector, but then they receive no non-pecuniary benefits from the job. An unmotivated agent has the ability to teach, but receives no nonpecuniary benefits. Other examples of mission-oriented sectors include hospitals, religious organizations, the army, non-governmental organizations carrying out relief and development work, as well as terrorist organizations such as Al Qaeda.

\subsection{Contracts and Matching}

The agent's reward can be conditioned on the outcome of the project. Thus, a contract is a

vector $c=\{e, w, b, x\}$ where $e$ is effort, $w$ is the fixed wage level, $b$ is a bonus payment for 
a successful project, and $x$ is a mission. ${ }^{10}$ The contract is feasible if and only if it satisfies three conditions - (i) it respects the agent's limited liability constraint, (ii) the effort level is incentive-compatible (iii) the principal and agent both get a non-negative expected payoff. Let $\mathcal{C}\left(p_{k}, a_{j}\right)$ be the set of feasible contracts for the pair $\left(p_{k}, a_{j}\right)$, and let $v_{k}^{p}(c)$ and $v_{j}^{a}(c)$ be the principal's and agent's expected payoffs for $c \in \mathcal{C}\left(p_{k}, a_{j}\right)$. Let

$$
\max _{c \in \mathcal{C}\left(p_{k}, a_{j}\right)}\left(v_{j}^{a}(c)\right) \equiv \bar{v}_{j k}^{a}
$$

be the maximum feasible payoff that an agent of type $a_{j}$ can obtain when contracting with a principal of type $p_{k}$. Later we show that our assumptions ensure that $\bar{v}_{j k}^{a}$ is a strictly positive real number and so $\mathcal{C}\left(p_{k}, a_{j}\right)$ is non-empty for every principal agent pair.

Contracts are determined by matched principal and agent pairs. Following Roth and Sotomayor (1989), the matching process can summarized by a one-to-one matching function $\mu: \mathcal{A}_{p} \cup \mathcal{A}_{a} \rightarrow \mathcal{A}_{p} \cup \mathcal{A}_{a}$ such that (i) $\mu\left(p_{k}\right) \in \mathcal{A}_{a} \cup\left\{p_{k}\right\}$ for all $p_{k} \in \mathcal{A}_{p}$ (ii) $\mu\left(a_{j}\right) \in \mathcal{A}_{p} \cup\left\{a_{j}\right\}$ for all $a_{j} \in \mathcal{A}_{a}$ and (iii) $\mu\left(p_{k}\right)=a_{j}$ if and only if $\mu\left(a_{j}\right)=p_{k}$ for all $\left(p_{k}, a_{j}\right) \in \mathcal{A}_{p} \times \mathcal{A}_{a}$. A principal (agent) is unmatched if $\mu\left(p_{k}\right)=p_{k}\left(\mu\left(a_{j}\right)=a_{j}\right)$. What this function does is to assign each principal (agent) to at most one agent (principal) and allows for the possibility that a principal (agent) remains unmatched, in which case he is described as "matched to himself".

An allocation for our economy is a matching described by $\mu$ and a set of contracts $c \in$ $\mathcal{C}\left(\mu\left(a_{j}\right), a_{j}\right)$ for all $\alpha_{j} \in \mathcal{A}_{p}$. We are interested in the properties of allocations that are optimal in two senses. First, principals are optimizing in the contracts that they offer to agents and, second, no pair of principals and agents could rematch and make themselves (strictly) better off.

Let $\underline{u}\left(a_{j}\right): \mathcal{A}_{a} \rightarrow\left[0, \bar{v}_{j k}^{a}\right]$ describe a vector of (feasible) "reservation payoffs" for each agent $a_{j}$ who is matched with a principal $p_{k}$. If an agent $a_{j}$ is matched with himself then $\underline{u}\left(a_{j}\right)=0$. An optimal contract will solve:

$$
\begin{gathered}
\max _{c \in \mathcal{C}\left(p_{k}, a_{j}\right)} v_{k}^{p}(c) \\
\text { subject to } \\
v_{j}^{a}(c) \geq \underline{u}\left(a_{j}\right)
\end{gathered}
$$

\footnotetext{
${ }^{10}$ We are following the convention that $e$ is part of the optimal contract so long as it satisfies the incentivecompatibility constraint.
} 
with the latter being the participation constraint of the agent. As we will see below, if $\underline{u}\left(a_{j}\right)$ is too small, the participation constraint will not bind. Denote the solution to the above contracting problem by $c^{*}\left(p_{k}, a_{j}\right)$. By varying $\underline{u}\left(a_{j}\right)$ over the suitable interval, this program allows us to solve for the (constrained) Pareto-frontier for any principal-agent match.

A matching $\mu$, with an associated set of optimal contracts $\left\{c^{*}\left(\mu\left(a_{j}\right), a_{j}\right)\right\}_{a_{j} \in \mathcal{A}_{a}}$ (or equivalently, $\left.\left\{c^{*}\left(p_{k}, \mu\left(p_{k}\right)\right)\right\}_{p_{k} \in \mathcal{A}_{p}}\right)$ is stable if and only if there is no pair $\left(p_{k}, a_{j}\right)$ and feasible contract $c \in \mathcal{C}\left(p_{k}, a_{j}\right)$ such that:

$$
\begin{aligned}
v_{k}^{p}(c)> & v_{k}^{p}\left(c^{*}\left(p_{k}, \mu\left(p_{k}\right)\right)\right) \\
& \text { and } \\
v_{j}^{a}(c)> & v_{j}^{a}\left(c^{*}\left(\mu\left(a_{j}\right), a_{j}\right)\right) .
\end{aligned}
$$

Intuitively, there is no principal-agent pair who would prefer to be matched with someone else other than their designated match. It follows immediately from the definition of stability that under a stable matching all matched allocations are Pareto efficient. Otherwise, principals and agents could re-match and at least one principal-agent pair would be better off.

\section{Analysis}

We first solve for optimal contracts for a given match of a principal of type $p_{k}$ and an agent of type $a_{j}$. We then study the implications of stable matching.

\subsection{Optimal Contracts}

The optimal contract solves:

$$
\max _{c} v_{k}^{p}=\theta_{k j}^{p}(x) e-\{e b+w\}
$$

subject to:

(i) The limited liability constraint $(L L C)$ requiring that the agent be left with at least $\underline{w}$ :

$$
b+w \geq \underline{w}, w \geq \underline{w}
$$

(ii) The participation constraint $(P C)$ of the agent that:

$$
v_{j}^{a}=e\left(b+\theta_{j k}^{a}(x)\right)+w-\frac{1}{2} e^{2} \geq \underline{u}\left(a_{j}\right)
$$


(iii) The incentive-compatibility constraint $(I C C)$ which stipulates that the effort level maximizes the agent's private payoff given $(b, w, x)$ since $e$ is not observable:

$$
e=\arg \max _{e \in[0,1]}\left(e\left(b+\theta_{j k}^{a}(x)\right)+w-\frac{1}{2} e^{2}\right) .
$$

Observe that $b$ can never exceed $\theta_{k j}^{p}(x)$ because the principal will then be receiving a negative expected payoff which is inconsistent with $c$ being a feasible contract. Similarly, it is not efficient to set $b<0$ (the $L L C$ requires that $b+l \geq w$ and so this is feasible only if $w>\underline{w}$ ) since by increasing $b$ and decreasing $w$ to keep the agent's utility constant, effort would go up and the principal would be better off. Therefore, the $I C C$ can be rewritten as:

$$
e=b+\theta_{j k}^{a}(x) \in(0,1)
$$

The solution to the above program divides into three sub-cases depending upon which of the above constraints bind. To state the results that follow, it is useful to define

$$
\hat{\theta}_{j k}(x)=\max \left\{\theta_{j k}^{a}(x), \theta_{k j}^{p}(x)\right\}+\theta_{j k}^{a}(x) .
$$

Then, the following Proposition characterizes the optimal contract in the mission-oriented sector. All proofs are presented in the Appendix:

Proposition 1: An optimal contract $\left(e_{j k}^{*}, b_{j k}^{*}, w_{j k}^{*}, x_{j k}^{*}\right)$ between the principal and agent pair $\left(p_{k}, a_{j}\right) \in \mathcal{A}_{p} \cup \mathcal{A}_{a}$ given a reservation payoff $\underline{u}\left(a_{j}\right) \in\left[0, \bar{v}_{j k}^{a}\right]$ exists, and has the following features:

(i) The fixed payment is set at the subsistence level, i.e., $w_{j k}^{*}=\underline{w}$

(ii) The bonus payment is characterized by

$$
b_{j k}^{*}=\max \left\{\sqrt{2 \psi_{j k}}-\theta_{j k}^{a}\left(x_{j k}^{*}\right), 0\right\}
$$

where $\psi_{j k}=\max \left\{\underline{u}\left(a_{j}\right)-\underline{w}, \frac{1}{8}\left(\hat{\theta}_{j k}\left(x_{j k}^{*}\right)\right)^{2}\right\}$.

(iii) The optimal effort level solves: $e_{j k}^{*}=b_{j k}^{*}+\theta_{j k}^{a}\left(x_{j k}^{*}\right)$.

(iv) The optimal mission is as follows: if $\omega_{a}>\omega_{p}$ then $x_{j k}^{*}=\frac{\alpha_{j}+\alpha_{k}}{2}$ while if $\omega_{a} \leq \omega_{p}$, then $x_{j k}^{*}=\frac{\omega_{a} \alpha_{j}+\omega_{p} \alpha_{k}}{\omega_{a}+\omega_{p}}$.

There are four main components of the contract. The first part of the proposition shows that the fixed wage payment is set as low as possible. This is intuitive: other than the agent's 
minimum consumption constraint, the agent is risk-neutral and does not care about the spread between his income in the two states. From the principal's point of view it is best to minimize $w$, since it has no effect on effort choice.

The second part characterizes the optimal bonus payment. There are three cases depending on which of the constraints in the optimal contracting problem is binding and whether or the principal or the agent values the outcome more:

Case 1: If the agent is more motivated than the principal and the outside option is low, then $b_{j k}^{*}=0$, i.e., there should optimally be no incentive pay.

Case 2: If the principal is more motivated than the agent and the outside option is low, then

$$
b_{j k}^{*}=\frac{1}{2}\left(\theta_{k j}^{p}\left(x_{j k}^{*}\right)-\theta_{j k}^{a}\left(x_{j k}^{*}\right)\right) .
$$

In this case, the principal sets incentive pay equal to half the difference in the principal and agent's valuation of success.

Case 3: If the outside option is high then

$$
b_{j k}^{*}=\sqrt{2\left(\underline{u}\left(a_{j}\right)-\underline{w}\right)}-\theta_{j k}^{a}\left(x_{j k}^{*}\right) .
$$

The optimal incentive pay, in this case, is set by the outside market with a discount which depends on the agent's motivation.

The third part of Proposition 1 gives the effort level. If effort were contractible, then it would be set equal to $\theta_{k j}^{p}(x)+\theta_{j k}^{a}(x)$. The principal can attain this, by setting the bonus payment equal to $\theta_{k j}^{p}(x)$. However, this will not maximize his expected payoff - he faces the usual trade-off between rent-extraction and incentive provision.

The last part of the Proposition characterizes the optimal mission choice. A simple tradeoff shapes the optimal mission. A mission closer to the agent's preferred outcome increases effort and hence allows the principal to offer a lower bonus payment. However, by moving the mission in this direction, the principal makes the project less valuable to himself. The result is typically a weighted average of the principal and agent's ideal missions, with the greater a party's motivation, the closer the chosen mission being to his ideal mission. However, if the agent is more motivated than the principal, then the principal would like to extract some of the agent's "excess" motivation by reducing the bonus payment, even though that would reduce 
effort. But the bonus is already zero in this case, and cannot be reduced any further due to limited liability. Therefore, the principal will partly increase his payoff by choosing a mission that is closer to his own preferred mission than what the weighted average formula suggests, although that reduces effort to some degree.

We now offer three corollaries of this proposition which are useful to understanding its implications for incentive design. The first describes what happens in the profit-oriented sector.

Corollary 1: An optimal contract $\left(e^{*}, b^{*}, w^{*}\right)$ in the profit-oriented sector for an agent of type $a_{j}(j=1,2, \ldots, M+1)$ whose reservation payoff is $\underline{u}\left(a_{j}\right) \in\left[0, \bar{v}_{j M+1}^{a}\right]$ exists, and has the following features:

(i) The fixed payment is set at the subsistence level, i.e., $w^{*}=\underline{w}$

(ii) The bonus payment is characterized by

$$
b^{*}=\sqrt{2 \psi_{j M+1}}
$$

where $\psi_{j M+1}=\max \left\{\underline{u}\left(a_{j}\right)-\underline{w}, \frac{1}{8} \pi^{2}\right\}$.

(iii) The optimal effort level solves: $e^{*}=b^{*}$.

A formal proof is in the appendix. But basically, it follows from Proposition 1 after plugging in $\theta_{M+1 j}^{p}=\pi$ and $\theta_{j M+1}^{a}=0$ (for all $j=1,2, . ., M+1$ ). Mission choice is no longer an issue. Moreover, case 1 above (bureaucratic incentives) is no longer a possibility - the agent in the profit oriented sector must always be offered incentive pay to put in effort.

Corollary 2: Greater principal-agent heterogeneity on missions reduces organizational efficiency.

Let $\Delta\left(p_{k}, a_{j}\right) \equiv\left|\alpha_{k}-\alpha_{j}\right|$ denote the extent of divergence in the principal's and agent's preferred mission. ${ }^{11}$ Note that the equilibrium effort level in cases 1 and 2 above is decreasing in $\Delta\left(p_{k}, a_{j}\right)$. Hence, organizations where agents and principals agree on mission preferences will have higher levels of productivity.

Corollary 3: Cross-sectionally, bonus payments and effort are negatively correlated.

\footnotetext{
${ }^{11}$ In case $1, e_{j k}^{*}=\omega_{a}\left(1-\frac{1}{8}\left[\Delta\left(p_{k}, a_{j}\right)\right]^{2}\right)$, while in case $2, e_{j k}^{*}=\frac{1}{2}\left\{\left(\omega_{p}+\omega_{a}\right)-\frac{1}{2} \frac{\omega_{p} \omega_{a}}{\omega_{p}+\omega_{a}}\left(\Delta\left(p_{k}, a_{j}\right)\right)^{2}\right\}$.
} 
To see this, observe that the bonus paid to the agent is decreasing in his motivation and is zero if the agent is more motivated than the principal. Moreover, the bonus is increasing in $\Delta\left(p_{k}, a_{j}\right){ }^{12}$ This, combined with Corollary 2 , implies the striking result that productivity (i.e., equilibrium effort) and incentive pay will be (weakly) negatively correlated across organizations. This is a pure selection effect capturing the characteristics of agents that affects both effort and incentive payments. Holding the characteristics of the principals and the agent constant, greater incentive pay would lead to higher effort and higher productivity.

The observation that productivity decreases in $\Delta\left(p_{k}, a_{j}\right)$ motivates the role of competition between principals in hiring agents as a means of raising organizational productivity. Both principals and agents can gain by improving sorting. In the next section, we explore this formally.

\subsection{Competition}

We now consider what happens when the sectors compete for agents. However, we do so without modeling the competitive process explicitly. We focus instead directly on the implications of stable matching. This says that any reasonable matching between principals and agents must be immune to a deviation in which any principal and agent can negotiate a contract which makes both of them strictly better off compared to the existing situation. Were this not the case then we would expect rematching to occur. We begin by showing that any stable matching must have agents in the mission-oriented sector matched with principals of the same type. This is stated as:

Proposition 2: Consider a matching $\mu$ and associated optimal contracts $\left\{c^{*}\left(\mu\left(a_{j}\right), a_{j}\right)\right\}_{j=1}^{M}$. Then this matching is stable only if $\Delta\left(\mu\left(a_{j}\right), a_{j}\right)=0$ for all $j=1, . ., M$.

This result says that all stable matches must have motivated principals and agents matched with one another. This argument is a consequence of the fact that, for any fixed set of reservation payoffs, an assortatively matched principal agent pair can always generate more

\footnotetext{
${ }^{12}$ For example, in case $2, b^{*}\left(p_{k}, a_{j}\right)=\frac{1}{2}\left(\theta_{p}-\theta_{a}\right)=\frac{1}{2}\left(\omega_{p}-\omega_{a}\right)\left\{1+\frac{1}{2} \frac{\omega_{p} \omega_{a}}{\left(\omega_{p}+\omega_{a}\right)^{2}}\left(\Delta\left(p_{k}, a_{j}\right)\right)^{2}\right\}$. Both $\theta_{a}$ and $\theta_{p}$ fall when $\Delta\left(p_{k}, a_{j}\right)$ goes up, but in this case $\theta_{a}$ falls relatively more as $x$ is already closer to the ideal mission preference of the principal.
} 
surplus than one where the principal and agent are of different types. ${ }^{13}$

This result allows us to focus on assortative matching. However, it leaves open the question of whether stable matches exist. We now construct two cases of stable matches which are economically interesting. The first arises when there is full-employment in the profit-oriented sector and the second when there is unemployment. We illustrate a stable matching in each case.

In the full employment case, the principals compete for agents who are scarce so that the latter can capture all the surplus in any stable outcome - otherwise an unmatched principal could "bid" for an agent who is matched with another principal by offering him a better contract. This sets a floor on the payoff that a motivated agent can be paid. Whether the voluntary participation constraint is binding now depends on how $\pi$ compares with $\omega_{a}$ and $\omega_{p}$. Let

$$
\hat{\omega}=\max \left\{\omega_{a}, \omega_{p}\right\}+\omega_{a} .
$$

Then we have a stable matching for this case as follows:

Proposition 3: Suppose that $n_{M+1}^{a}<n_{M+1}^{p}$ (full employment in the profit-oriented sector). Then the following matching $\mu$ is stable:

(i) $\Delta\left(\mu\left(a_{j}\right), a_{j}\right)=0$ for all $j=1, . ., M$ and $\mu\left(a_{M+1}\right)=p_{M+1}$.

(ii) $w^{*}\left(\mu\left(a_{j}\right), a_{j}\right)=\underline{w}$ for all $j=1, \ldots, M+1$

(iii) The bonus payment in the mission-oriented sector is:

$$
b^{*}\left(\mu\left(a_{j}\right), a_{j}\right)=\frac{1}{2} \max \left\{\hat{\omega}, \pi+\sqrt{\pi^{2}-4 \underline{w}}\right\}-\omega_{a}
$$

for all $j=1, \ldots, M$.

(iv) The bonus payment in the profit oriented sector is:

$$
b^{*}\left(\mu\left(a_{M+1}\right), a_{M+1}\right)=\frac{\pi+\sqrt{\pi^{2}-4 \underline{w}}}{2} .
$$

Thus the stable matching outcome has perfect sorting on motivation - motivated principals and agents are matched on mission preferences and the unmotivated principals are matched

\footnotetext{
${ }^{13}$ Recent results on assortative matching in non-transferable utility environments by Legros and Newman (2003) cannot be applied here because of the specific nature of the preferences over missions. See Appendix B for further discussion.
} 
with the unmotivated agents. Such pairings yield the highest (second-best) surplus for the relevant principals and agents which makes other matches unstable. With full employment in the profit-oriented sector, the expected payoff of unmotivated principals is driven down to zero and unmotivated agents capture all the surplus from profit-oriented production. In the situation described in proposition 3, the reservation utility of a motivated agent is set by what he could obtain by switching to the mission-oriented sector. ${ }^{14}$

Comparing Propositions 1 and 3, two roles of competition can be seen. First, there is a matching effect whereby smaller values of $\Delta\left(p_{k}, a_{j}\right)$ boosts organizational productivity and economizes on the need for incentive pay in the mission-oriented sector. Second, there is an outside option effect - if the profit-oriented sector is sufficiently productive (i.e., $\left.\pi+\sqrt{\pi^{2}-4 \underline{w}}>\hat{\omega}+\omega_{a}\right)$ then the mission-oriented sector the participation constraint will bind, increasing pay and an agent's productivity.

This matched outcome gives an exact sense of when incentives will be less high-powered in mission-oriented production with motivated agents. When the participation constraint binds in the mission-oriented sector, incentive pay is at the private sector level less $\omega_{a}$. Without the participation constraint binding, incentive pay in the mission-oriented sector is zero if $\omega_{a}>\omega_{p}$, and so once again, incentives is more high powered in the profit-oriented sector. However, it is possible to have more high-powered incentives in mission-oriented sector than in the profitoriented sector. This is when the participation constraint is not binding, and $\omega_{p}$ is very high relative to $\pi$ and $\omega_{a}$.

If there is unemployment in the profit-oriented sector, an unmotivated principal should be able to extract all the surplus from this agent (at least in so far as the limited liability constraint permits). This implies that the supply price of motivated agents is determined by their unemployment payoff. For this case, we have the following example:

Proposition 4: Suppose that $n_{M+1}^{a}>n_{M+1}^{p}$ (unemployment in the profit-oriented sector). Then the following matching $\mu$ is stable:

(i) $\Delta\left(\mu\left(a_{j}\right), a_{j}\right)=0$ for all $j=1, . ., M$ and $\mu\left(p_{M+1}\right)=a_{M+1}$.

\footnotetext{
${ }^{14}$ While we have picked this solution to show why payoffs in the profit-oriented and mission-oriented sector can be tied together, there is in fact a range of reservation utilities for motivated agents which support an equilibrium with assortative matching. The situation that we are describing in Proposition 3 , is that stable outcome which gives most surplus to the motivated principals.
} 
(ii) $w^{*}\left(\mu\left(a_{j}\right), a_{j}\right)=\underline{w}$ for all $j=1, \ldots, M+1$

(iii) The bonus payment in the mission-oriented sector is

$$
b^{*}\left(\mu\left(a_{j}\right), a_{j}\right)=\frac{1}{2} \hat{\omega}-\omega_{a}
$$

for all $j=1, \ldots, M$ and the bonus payment in the profit oriented sector is

$$
b^{*}\left(\mu\left(a_{M+1}\right), a_{M+1}\right)=\frac{\pi}{2} .
$$

This result differs in a couple of interesting ways from Proposition 3 although the thrust of the argument is preserved, namely, stable outcomes involve matching motivated principals and agents on similarity of mission preferences, and matching unmotivated principals with unmotivated agents. The presence of unemployment unhinges incentives in the missionoriented and profit-oriented sectors of the economy since the only outside option is being unemployed. Principals and employed agents in both sectors earn a rent.

\section{Applications}

Contrasting the results in Proposition 1 with those in Propositions 2, 3 and 4 yields some insight into the role of competition in the mission-oriented sector and its role in improving productivity and changing incentives. The results in Propositions 2, 3 and 4 correspond to an idealized situation of frictionless matching. They provide a benchmark for what can be achieved with decentralized provision where principals have autonomy over mission choice. So long as all principals and agents in the mission-oriented sector have the same levels of motivation $\left(\omega_{p}\right.$ and $\left.\omega_{a}\right)$ in equilibrium all agents get the same compensation package and the productivity of each firm is the same, even though they differ in terms of missions. The results also emphasize how matching can increase organizational efficiency with limited use of high powered incentives. For the purposes of applications, Propositions 2, 3 and 4 correspond to a case where frictions are small or the outcome in the long-run.

Reality can diverge from this ideal in two main ways. In some cases (especially where mission-oriented production is public), the principal may be restricted in the mission that he can adopt. Some firms may therefore be unable to adapt the mission to suit agent's mission preferences. For example, constitutional restrictions in the U.S. do not allow public funding 
of religious organizations even though there may be many teachers who would be motivated by teaching to a religious curriculum. The model predicts that this leads to a loss of productivity.

Another source of divergence is the presence of natural and artificial frictions to matching implying that our idealized matching outcome may not be realized. If this is the case, then firms within the mission-oriented sector will differ not only in terms of the mission, but also in terms of the contracts, and levels of productivity. The results in Proposition 1 hold for an any optimal contract - including those where principals and agents are not matched on mission preferences. They emphasize how poor alignment of principals and agents in terms of mission-preference lead to a greater need for monetary incentives. Thus, Proposition 1 provides a benchmark for cases where matching is poor. For the purposes of applications we will interpret this as a case where either market frictions are large, or possibly a "short-run" analysis where matches can be taken as fixed.

The results in Propositions 3 and 4 also give some sense of the link between the contracts offered in the mission-oriented sector and those offered in the profit-oriented sector. For some applications, this is important.

\subsection{School Competition}

The approach generates insights into the role of competition in fostering improved school performance. The overview in Hoxby (2003) confirms that relatively little theoretical work has been done on determinants of school productivity even though the empirical literature suggests that there are productivity differences across schools and that competition may affect these. ${ }^{15}$

The competitive outcome that we characterize can be thought of as the outcome from an idealized system of decentralized schooling in which schools compete by picking different kinds of curriculum and attracting teachers who are most motivated to teach according to that curriculum. One element of the curriculum could, for example, be whether religious instruction is included. Well matched schools can forego incentive pay and rely exclusively on agents' motivation. This explains why some schools (such as Catholic schools) can be more

\footnotetext{
${ }^{15}$ Hoxby (1999) is a key exception. She models the impact of competition in a model where there are rents in the market for schools, and argues that a Tiebout like mechanism may increase school productivity. Other approaches to the issue, such as Epple and Romano (2002), have emphasized peer-group effects (i.e., school quality depends on the quality of the mean student) but as far as "supply side" factors are concerned they assume that some schools are more productive than others for exogenous reasons.
} 
productive by attracting teachers whose mission-preferences are closely aligned with those of the school management. More generally, a decentralized schooling system where missions are developed at the school level will tend to be more productive (as measured in our model by equilibrium effort) than a centralized one in which a uniform curriculum (mission) is imposed on schools by government.

The approach offered here is distinct from existing theoretical links competition and productivity in the context of schools. For example, yardstick competition has been used extensively in the U.K. where "league tables" are used to compare school performance. Whether such competition is welfare improving in the context of schools is moot since the theoretical case for yardstick comparisons is suspect when the incentives in organizations are vague or implicit as in the case of schools (see, for example, Dewatripont, Jewitt and Tirole (1999)). Another possible paradigm for welfare-improving school competition rests on the possibility that it can increase the threat of liquidation with a positive effect on teacher effort (Schmidt, 1997). This possibility could easily be incorporated into our model as a force that increases the cost to the agent (in this case a teacher) of the outcome where the output is $Y_{L}$.

These different roles of competition can be studied in our contracting framework without the implausible assumption of profit maximization as the school objective. Moreover, the model works equally well for publicly owned and privately owned schools. ${ }^{16}$ It also suggests a novel mechanism by which voucher competition can enhance school productivity by allowing parents to find the school with the best match between their curriculum needs (parents' mission preferences) and schools.

The model abstracts from stratification due to principal and agents differing in their motivation by considering matching only in terms of mission preferences. As a result, in the decentralized equilibrium of our model, all schools are equally productive even though they are differentiated by mission. The analysis can be extended to allow principals and agents to differ in their motivation levels (different $\omega$ 's). Appendix $B$ shows that we have assortative matching in this case. More motivated agents receive higher bonus payments. The outcome now involves inequality within the mission-oriented sector in terms of payoffs and expected

\footnotetext{
${ }^{16}$ The model is relevant for the kinds of quasi-markets reforms encouraing competition within the public sector. These have been experimented with extensively in the U.K. (see, for example, Legrand and Bartlett
} (1993)) 
output. Competition between schools will then lead to segregation effects, emphasized by authors such as Epple and Romano (2002).

Diversity in missions can, in some cases, generate negative externalities. This is particularly so when missions are likely to be driven by ideology, religious or political, and one concern with horizontally differentiated schools could be that society could end up being very fragmented with a negative consequence for the solution of collective action problems. This could lead to reasons why the state would wish to restrict the missions adopted by schools.

\subsection{Nonprofit Organizations}

The notion of a mission-oriented organization staffed by motivated agents corresponds well to many views of non-profit organizations. The model emphasizes why those who care about a particular cause are likely to end up as employees in mission-oriented non-profits. This finds support in Weisbrod (1988), who observes that "Non-profit organizations may act differently from private firms not only because of the constraint on distributing profit but also, perhaps, because the motivations and goals of managers and directors ... differ. If some non-profits attract managers whose goals are different from those managers in the proprietary sector, the two types of organizations will behave differently." (page 31). He also observes that "Managers will ... sort themselves, each gravitating to the types of organizations that he or she finds least restrictive - most compatible with his or her personal preferences" (page 32). ${ }^{17}$

Weisbrod also cites persuasive evidence to support the idea that such sorting is important in practice in the non-profit sector. However, the discussion in Weisbrod (1988)) overly emphasizes the role of the non-profit constraint rather than the more primitive notion of mission-orientation. Militant organizations such as Al Qaeda, the Irish Republican Army, or Peru's Sendero Luminoso (The Shining Path) are able to sort workers on mission preferences without necessarily using anything like a non-profit constraint. ${ }^{18}$ We also regard such sorting as important in "socially responsible" for-profit firms such as the Body Shop. ${ }^{19}$ How exactly a

\footnotetext{
${ }^{17}$ See Glaeser (2002) for a model of non-profits where workers and managers of non-profits have something like our mission-preferences, i.e., caring directly about the output of the firm.

${ }^{18}$ For instance, it is often alleged that some militant organizations fund their operations using profits from drug-trafficking (see, for example, the website of The Bureau for International Narcotics and Law Enforcement Affairs (INL), http://www.state.gov/g/inl/).

${ }^{19}$ On the website of the Body Shop, their "values" are described as follows: "We consider testing prod-
} 
non-profit status facilitates greater sorting on missions, or a commitment to corporate responsibility by for-profit firms enhances efficiency (even though some of these measures, like in the case of the Body Shop might be costly) by attracting a motivated workforce raise interesting questions and are explored in depth in Besley and Ghatak (2003).

Empirical studies suggest that in industries where both for-profits and non-profits are in operation, such as hospitals, the former sector make significantly higher use of performancebased bonus compensation relative to base salary for managers (Ballou and Weisbrod, 2002 and Bertrand, Hallock, and Arnould 2003). It is recognized in the literature that managers may care about the outputs produced by the hospital or the patient. However, researchers are unable to explain this empirical finding. In the words of Ballou and Weisbrod (2002): "While the compensating differentials may explain why levels of compensation differ across organizational forms, it does not explain the differentials in the use of strong relative to weak incentives." Our framework provides a simple explanation for this finding. In addition, Bertrand, Hallock, and Arnould (2003) find that the spread of managed care in the US, which increases market competition, induced significant changes in the behavior of non-profit hospitals. In particular, although the relationship between economic performance and top managerial pay in nonprofit hospitals is on average weak, they found that it strengthens with increases in HMO penetration. In terms of our model, this can be explained as the effect of an increase in the profitability of the for-profit sector $(\pi)$ which tightens the participation constraints of the managers.

Our framework also underlines the value of diversity in the mission-oriented sector provided that there are variety of views in the way in which public goods should be produced (as represented by the mission preferences). Weisbrod (1988) emphasizes the important of nonprofit organizations in achieving diversity in the provision of collective goods. He observes that non-profits will likely play a more important role in situations where there is greater underlying diversity in preferences for collective goods. For example, he contrasts the U.S. and Japan suggesting that greater cultural heterogeneity of the U.S. is partly responsible for the greater importance of non-profit activity in the U.S.. Our analysis of the role of competition in sorting principals and agents on mission preferences underpins the role of diversity in achieving ucts or ingredients on animals to be morally and scientifically indefensible" and "We believe that a business has the responsibility to protect the environment in which it operates, locally and globally" (see http://www.thebodyshop.com/). 
efficiency. Better matched organizations can result in higher effort and output. Hence, diversity is not only good for the standard reason, namely, consumers get more choice, but also in enhancing productive efficiency.

\subsection{Funding of Mission-Oriented Organizations}

A key insight of the approach taken here lies in being able to see how organizational productivity is affected by various regimes for financing mission-oriented organizations. While a complete treatment of fund raising lies beyond the scope of this paper, we can develop some simple implications which hint at the issues. Suppose, following Glaeser (2002) that there is a third group of actors (donors) who are willing to pay an amount $D(x)$ to finance missionoriented activity. ${ }^{20}$ Whether the donor is a relevant player depends upon the wealth of the agent.

Consider an organization in which the principal and agent are matched with common mission preference $\alpha_{0}$, and $\omega_{a}=\omega_{p}=\omega_{0}$. Consider the case where the $P C$ is not binding for the agent. Then, using the result in Proposition 1, the organization would provide a fixed wage of $\underline{w}$ and no bonus for high output. The cost of financing such a mission-oriented organization with mission $\alpha_{0}$ is therefore just $\underline{w}$. Moreover, the effort level is $e^{*}=\omega_{0}$.

Now consider two possible cases depending on the size of the principal's initial wealth $A$. If $A>\underline{w}$, then the analysis is unchanged and the principal does not seek donations to finance the organization. The other case is where $A<\underline{w}$. Now suppose that donations are given by:

$$
D(x)=\kappa \cdot e^{*}(x) \omega_{D}\left\{1-\frac{1}{2}\left(\alpha_{D}-x\right)^{2}\right\}
$$

where $0<\kappa \leq 1, e^{*}(x)=\omega_{0}\left[1-\frac{1}{2}\left(\alpha_{0}-x\right)^{2}\right]$, and the payoff of the donor is $\theta^{D}=\omega_{D}\{1-$ $\frac{1}{2}\left(\alpha_{D}-x\right)^{2}$ with $\omega_{D}$ being his motivation. The parameter $\kappa$ crudely captures how much of the potential willingness to pay can be captured from donors. The latter takes into account the fact that changing the mission away from $\alpha_{0}$ reduces the agent's effort. The principal will now have to pick the mission to satisfy:

$$
\kappa \cdot e^{*}(x) \omega_{D}\left\{1-\frac{1}{2}\left(\alpha_{D}-x\right)^{2}\right\} \geq A-\underline{w}
$$

\footnotetext{
${ }^{20}$ This abstracts from competition in the market for donors in which case $D(\cdot)$ would depend upon the $x$ 's of all the other mission oriented organizations in economy to whom the donor could give.
} 
assuming that a mission exists that satisfies this equation. ${ }^{21}$ Then if

$$
\kappa \cdot \omega_{0} \omega_{D}\left\{1-\frac{1}{2}\left(\alpha_{D}-\alpha_{0}\right)^{2}\right\}>A-\underline{w}
$$

the organization will pick the mission $x=\alpha_{0}$. However if

$$
\kappa \cdot \omega_{0} \omega_{D}\left\{1-\frac{1}{2}\left(\alpha_{D}-\alpha_{0}\right)^{2}\right\}<A-\underline{w}
$$

then there will be a need to change the mission to satisfy the donor even though the cost is that it will reduce organizational efficiency. If the mission has to be sufficiently distorted to attract donations, then the organization may have to resort to incentive pay to increase effort. In this case, the cost of running the organization can increase and the need to chase donations becomes more pressing. It is even possible that chasing donations becomes self-defeating. ${ }^{22}$

Two observations follow from this. First, organizations where donor and organization preferences are more closely matched are more likely to be financially viable and will be more productive. Indeed, efficient organization of the mission-oriented sector requires matching of donors with principals and agents mission preferences. Second, organizations which have large endowments (for example, the Gates Foundation) will tend to be more productive as they are less likely to have to adjust their missions to attract donors.

The role of the donor can also give some insight into the role of public finance. Government can play the role of donor with its mission preferences determined either by electoral concerns or constitutional restrictions (e.g., maintaining a neutral stance with respect to religious issues). The government may be able to provide financial support to some private organizations but if it does so, it might tend to distort their missions towards its preferred style of provision. But in doing so, it can reduce productivity since agents will be less motivated as a consequence. Indeed, when the US President George W. Bush announced the policy of federal support for faith-based programs in 2001, some conservatives expressed concerns that involvement with the government will cost churches intensity and integrity. ${ }^{23}$ Thus, we would expect government

\footnotetext{
${ }^{21} \mathrm{~A}$ neccessary condition for this is that $\kappa \omega_{0} \omega_{D}>A-\underline{w}$.

${ }^{22}$ This is a short-run perspective taking the match between principals, agents and donors as fixed. In the long-run, matching principals and agents to donor preferences should serve a role to increase organizational efficiency.

${ }^{23}$ See "Leap of Faith" by Jacob Weisberg, February 1, 2001, Slate (http://www.slate.msn.com).
} 
funded organizations on average to be less efficient than those privately financed through endowments. However, whether they are more or less productive than those funded by private donations is less clear given the earlier discussion.

A variety of extensions of the approach could be developed to understand how missionoriented organizations structure themselves to provide the best incentives for donors and managers. Donors are more likely to support mission-oriented organizations when they believe that they will deliver their preferred mission. This will require a credible mission statement and high effort from a motivated staff. In practice credibility may be an issue if the activities of the organization are hard to monitor. Clearly, the non-profit mandate which is frequently adopted by many mission-oriented organizations is one way of doing this. However, others measures to guarantee dedication to the mission include advertising, and appointing oversight committees such as trustees.

\subsection{Incentives in Public-Sector Bureaucracies}

Disquiet about traditional modes of bureaucratic organization has lead to a variety of policy initiatives to improve productivity in the public sector. The so-called New Public Administration emphasizes the need to incentivize public bureaucracies and to empower consumers of public services. ${ }^{24}$ Relatedly, Osborne and Gaebler (1993) describe a new model of public administration emphasizing the scope for dynamism and entrepreneurship in the public sector. Our framework suggests an intellectual underpinning for these approaches. However, by focussing on mission-orientation, which is also a central theme of Wilson (1989), we emphasize the fundamental differences between incentive issues in the public sector and those that arise in standard private organizations.

The results developed here give some insight into how to offer incentives for bureaucrats when there is a competitive labor market. Our framework implies that public sector incentives are likely to be more low-powered because it specializes in mission-oriented production. It therefore complements existing explanations based on multi-tasking and multiple principals for why we would expect public sector incentives to be lower powered than private sector incentives (Dixit, 2002). It provides a particularly clean demonstration of this as the production technology is assumed to be identical in all sectors.

\footnotetext{
${ }^{24}$ See Barzelay (2001) for background discussion.
} 
In a public bureaucracy, we might think of the principal's type being chosen by an electoral process. The productivity of the bureaucracy will change endogenously if there is a change in the mission if the principal is replaced. Incumbent agents who were matched to the outgoing principal will resist efforts to change the mission by the new principal. To the extent the mission is changed, the organizational productivity (reflecting equilibrium effort choices by agents) will fall, other things being equal. Organizations without selection on mission, such as profitoriented firms, will not face this demoralizing effect. This provides a possible underpinning for the difficulty in re-organizing public-sector bureaucracies and a decline in morale during the process of transition. Over time, as the matching process adjusts to the new mission, this effect can be undone and so we might expect the short and long-run responses to change to be rather different. As Wilson (1989, p. 64) remarks, in the context of resistance to change in bureaucracies by incumbent employees, "..one strategy for changing an organization is to induce it to recruit a professional cadre whose values are congenial to those desiring the change." This suggests a potentially efficiency-enhancing role for politicized bureaucracies where the agents change with changes in political preferences.

The approach also gives some insight into how changes in private sector productivity necessitate changes in public sector incentives. Changes in productivity that affect both sectors in the same way will have a neutral effect. However, unbalanced productivity changes that affect one sector only may have implications for optimal contracts. To see this, consider an exogenous change in $\pi$. Suppose that this is a situation of full employment as described in Proposition 3. In the case where the voluntary participation is constraint is not binding public and private incentives are unhinged. However, eventually increases in private-sector productivity $(\pi)$ will have a bite on public-sector incentives and without some concomitant increase in $\omega_{a}$ and $\omega_{p}$, incentives will become higher-powered. In the unemployment case described in Proposition 4, private-sector productivity does not affect public-sector productivity. Hence, we would expect issues concerning the interaction between public and private pay to arise predominantly in tight labor markets.

Putting these arguments together, the model casts light on why the arguments of the New Public Management to promoting incentives in the public sector can become popular, as it did in countries like New Zealand and the U.K. in the 1980s. The U.K. experienced a fall in $\omega_{p}$ under the Prime Ministership of Margaret Thatcher. But with a slack labour market there 
was little consequence for public sector incentives even though it signalled a relative fall in the desire for some mission-oriented activity in the public sector. However, in the 1990s with a return to full employment and rising $\pi$ the situation changed, causing the public sector to increasingly resort to schemes that mimic private sector incentives.

Another aspect of organizational change in the public sector has been moves to empower beneficiaries of public programs. Examples include attempts to involve parents in the decisionmaking process of schools and patients in that of the public health system. This is based on the view that public organizations work better when members of their client group get representation and can help to shape the mission of the organization. The model developed here suggests that this works well provided that teachers and parents share similar educational goals. Otherwise, attempts by parents to intervene will simply increase mission conflict which can reduce the efficiency of organizations. Again, we might expect significant differences between short and long run responses when matching is endogenous.

\subsection{Corruption}

We have so far emphasized agent motivation of a non-pecuniary variety. However, there are cases where agents are motivated due to the attenuation of the principal's property rights they can steal the output of the project. We show that allowing agent motivation through this channel does not typically lead to improvements in organizational efficiency.

To see this, suppose that all motivated principals and agents are identical with $\theta_{a}=\mu R$ and $\theta_{p}=\pi-R$, where $R$ is the amount that the agent "steals" from the principal. The cost of stealing is parametrized by $\mu \leq 1$. Assume for simplicity that the agent's outside option is zero.

Just as above, the agent is motivated as he gets an independent payoff from putting in effort. However, the fact that this is a monetary payoff that comes at the expense of the principal is important and completely alters the thrust of the results. To see, we derive the optimal incentive contract in this case. It is easy to check that the optimal incentive scheme is now:

$$
\left(b^{*}, w^{*}\right)=\left(\frac{\pi-(1+\mu) R}{2}, \underline{w}\right) .
$$


The corresponding effort level is

$$
e^{*}=b^{*}+\mu R=\frac{\pi-(1-\mu) R}{2} .
$$

The expected payoffs of the principal, and the agent are $v^{p}=\frac{1}{4}(\pi-R(1-\mu))^{2}-\underline{w}$ and $v^{a}=\frac{1}{8}(\pi-R(1-\mu))^{2}+\underline{w}^{25}$

Therefore, so long as $\mu<1$, both the principal and agent are worse off because of corruption. Also, the productivity of the organization is decreasing in $R$ in this case. This is because the joint surplus is smaller when the agent steals as the benefit to the agent is smaller than the cost to the principal. The agent would ideally wish to commit not to steal. Interestingly, for given $R$, the productivity of the organization as well as the payoffs of the principal and the agent are all increasing in the efficiency of the stealing technology, i.e., $\mu$. When $\mu=1$, the fact that the agent steals has no impact on incentives. The principal simply adjusts the bonus payment of the agent to offset any stealing by him. In this case, the effect of stealing is irrelevant.

This example emphasizes the importance of the fact that agent motivation must come from value-enhancing activities, i.e. those that raise the joint surplus of the principal and agent. Agent motivation through transfers does not enhance efficiency and strictly reduces it when the transfer technology is inefficient.

\subsection{Incentives to Innovate}

A common complaint about the public sector is that it is conservative and lacks the will to innovate. Religious organizations, advocacy groups, and NGOs are often accused of being rigid in their views and approaches. Our model reveals a fundamental sense in which this will be the case in mission-driven organizations with motivated agents. This is because innovations are likely to generate a conflict of interest in mission-driven organizations. In contrast, in profit-driven organizations any innovation that raises profits ( $\pi$ in terms of our model) will not be resisted by anybody. ${ }^{26}$

\footnotetext{
${ }^{25}$ Since the agent gets a monetary payoff from the project, the limited liability constraint is partly relaxed and it is possible to have $b^{*}<0$ as long as $b \geq-\mu R$. However, as can be seen from the expression for effort, $b$ will never be set equal to $-\mu R$.

${ }^{26} \mathrm{We}$ are considering innovations that increase joint surplus (which equals profits for profit-driven organizations) without any changes in the underlying technology. In contrast, even in profit-driven organizations, innovations that change the relative importance of various factors of production, or the nature of the agency
} 
Suppose then that there is an innovation $\delta \in\{0,1\}$ which can be costlessly implemented. Let $\left\{\theta_{k}^{p}\left(a_{j}, x, \delta\right), \theta_{j}^{a}\left(p_{k}, x, \delta\right)\right\}$ be the payoffs of the principal and agent as a function of the innovation.

First, consider the profit-oriented sector of the economy and suppose that $\theta_{M+1}^{p}\left(a_{j}, x, 1\right)=$ $\pi_{1}>\theta_{M+1}^{p}\left(a_{j}, x, 0\right)=\pi_{0}$, with the payoff of the agent (who is always unmotivated in this sector) unaffected. In this case, the principal and the agent both prefer to implement the innovation if it raises the principal's payoff. ${ }^{27}$

Now consider an innovation in the mission-oriented sector. Suppose that the principal and agent are perfectly matched and let $\left(\omega_{p}(\delta), \omega_{a}(\delta)\right)$ be the principal's and agent's motivations as a function of the innovation. We now consider the conditions under which either will support the innovation.

Suppose that $\omega_{a}(\delta)>\omega_{p}(\delta)$ for $\delta \in\{0,1\}$. Then the principal will wish to innovate if and only if

$$
\omega_{a}(1) \omega_{p}(1)>\omega_{a}(0) \omega_{p}(0)
$$

while the agent desires the innovation if and only if

$$
\omega_{a}(1)>\omega_{a}(0)
$$

From a joint surplus-maximizing point of view the innovation is desirable if and only:

$$
S(1)>S(0)
$$

where $S(\delta)=\omega_{a}(\delta)+\omega_{p}(\delta)$. Clearly if $\omega_{a}(1)>\omega_{a}(0)$ and $\omega_{p}(1)>\omega_{p}(0)$ then the innovation is desirable on all three grounds. It is clear that if the innovation reduces either $\omega_{a}(\delta)$ or $\omega_{p}(\delta)$, then either the principal or the agent may be opposed to it even if it raises joint surplus.

Above we assumed no transfers. Given the assumption of limited wealth on the part of the agent, transfers from the agent to the principal are not feasible, although transfers from the principal to the agent are possible. Still, the general point that the innovations are less likely to be implemented in mission-oriented organizations than in profit-oriented organizations holds.

\footnotetext{
problem, may generate conflicts of interest.

${ }^{27}$ If the voluntary participation constraint is not binding, both would strictly prefer the innovation. Otherwise, the principal would be strictly better off, but the agent will be indifferent.
} 


\section{Concluding Comments}

This paper studies competition and incentives in mission-oriented production. These ideas apply best to the production of collective goods whether in the public or private sectors. We have emphasized how mission design affects incentives and that monetary incentives are really only a feature of dysfunctionality within an organization. Competition plays an important sorting role which increases the efficiency of mission oriented production.

While we have emphasized the virtues of mission-orientation and matching, it is important to remember that it is equally relevant in the production of collective bads. The basic model fits terrorist groups and extremist organizations like the Klu Klux Klan. Thus the welfare implications of our model are far from obvious even though the positive implications of incentive structures and productive efficiency apply.

Our approach cuts across the conventional public-private divide largely by studying contracts rather than institutions. While the study of institutions is important, it has lead to too large a divide between the literatures on non-profit firms and governments. However, an important next step is to understand different institutional forms. In terms of the current approach, this must lie in the way that institutions restrict or enhance contracting possibilities. One key aspect of this is the accountability mechanism faced by principals under private and public provision, the former being subject to oversight by trustees and the latter to electoral discipline. Government and non-governmental organizations also differ in organizational scope - government is typically part of a larger multi-service provider. These are important issues for future study.

The model also provides a framework for studying why organizations may eschew the profit motive. For example, if the mission choice is not perfectly contractible, non-profit status may be one way for the principle to credibly commit not to change the mission ex post as it effectively reduces the power of the principal to act as a residual claimant (see Besley and Ghatak (2003)). This can be a good idea in our model if as a consequence agent motivation increases. Another aspect of limiting the profit motive is socially responsible business practices. Our model suggests that this can increase productivity within firms if it increases agent motivation. ${ }^{28}$ Thus, socially responsible firms can also be more productive.

\footnotetext{
${ }^{28}$ Alternatively, if the types of principals or agents are unobservable, these measures can be good signalling or screening devices.
} 


\section{References}

[1] Acemoglu, Daron, Michael Kremer and Atif Mian, [2003], "Incentives in markets firms and governments," typescript.

[2] Ackerberg, Daniel and Maristella Botticini [2002]: "Endogenous Matching and Empirical Determinants of Contractual Form", Journal of Political Economy, 110(3), 564-91.

[3] Aghion, Philippe and Jean Tirole, [1997], "Formal and Real Authority in Organizations," Journal of Political Economy, 105(1): 1-29.

[4] Akerlof, George and Rachel Kranton, [2003], "Identity and the Economics of Organizations," typescript.

[5] Alesina, Albert and Guido Tabellini, [2003], "Bureaucrats or Politicians," typescript.

[6] Bertrand, Marianne, Kevin F. Hallock, and Richard Arnould [2003]: "Does Managed Care Change the Mission of Nonprofit Hospitals? Evidence From the Managerial Labor Market", Working Paper, GSB, Chicago, and University of Illinois.

[7] Ballou, Jeffrey P. and Burton A. Weisbrod [2002]: "Managerial rewards and the behavior of for-profit, governmental, and nonprofit organizations: evidence from the hospital industry", Forthcoming, Journal of Public Economics.

[8] Barzelay, Michael (2001): The New Public Management - Improving Research and Policy Dialogue, Berkeley \& Los Angeles: University of California Press.

[9] Bénabou, Roland and Jean Tirole [2003]: "Intrinsic and Extrinsic Motivation", Forthcoming, Review of Economic Studies.

[10] Besley, Timothy and Maitreesh Ghatak [2003]: "Efficient Restraints on the Profit Motive: Theory and Applications to Corporate Responsibility and Non-Profit Organizations", Work in Progress.

[11] Blume, Lawrence and Carl P. Simon, [1994], Mathematics For Economists, W.W. Norton and Co., New York, London. 
[12] Crawford, Vincent and Joel Sobel, [1982], "Strategic Information Transmission," Econometrica, 50, 1431-1452.

[13] Dam, Kanishka and David Perez-Castrillo [2001]: "The Principal-Agent Matching Market", Working Paper, Universitat Autonoma de Barcelona.

[14] Dewatripont, Mathias, Ian Jewitt and Jean Tirole [1999], "The Economics of Career Concerns," Review of Economic Studies, 66(1), 189-217.

[15] Dixit, Avinash [2001]: "Incentive Contracts for Faith-Based Organizations to Deliver Social Services," unpublished typescript.

[16] Dixit, Avinash [2002]: "Incentives and Organizations in the Public Sector: An Interpretive Review," Journal of Human Resources, Fall 2002.

[17] Epple, Dennis and Richard Romano [2002]: "Educational Vouchers and CreamSkimming", NBER Working Paper \#9354.

[18] Francois, Patrick [2000]: "Public Service Motivation as an Argument for Government Provision" Journal of Public Economics, 78, 275-299.

[19] Frey, Bruno S., [1997], Not Just for the Money: An Economic Theory of Personal Motivation, Cheltenham: Edward Elgar Publishing.

[20] Glaeser, Edward, [2002], "The Governance of the Not-For-Profit Sector," Harvard Institute for Economic Research Discussion Paper No. 1954.

[21] Hart, Oliver, and Bengt Holmstrom, [2002], "Vision and Scope of the Firm," unpublished typescript, Harvard and MIT.

[22] Holmstrom, Bengt, and Paul Milgrom [1991]: Multi-task Principal-Agent Analysis: Incentive Contracts, Asset Ownership, and Job Design" Journal of Law, Economics and Organization, 7 (Special Issue), 24-52.

[23] Hoxby, Caroline M., [1999], "The Productivity of Schools and Other Local Public Goods", Journal of Public Economics, 74(1), 1-30. 
[24] Hoxby, Caroline M., [2002], " School Choice and School Productivity (or Could School Choice be a Tide that Lifts All Boats?)," NBER Working Paper No. w8873.

[25] Lazear, Edward P., [2000], "Performance Pay and Productivity," American Economic Review, 90(5), 1346-1361.

[26] LeGrand, Julian and Will Bartlett, [1993], Quasi-Markets and Social Policy, London: MacMillan.

[27] Legros Patrick and Andrew F. Newman, [2003], "Beauty is a Beast, Frog is a Prince: Assortative Matching with Nontransferabilities," typescript.

[28] Murdock, Kevin, [2002], "Intrinsic Motivation and Optimal Incentive Contract," Rand Journal of Economics, 33(4), 650-671.

[29] Osborne, David and Ted Gaebler, [1993], Reinventing Government: How the Entrepreneurial Spirit is Transforming the Public Sector, New York: Plume Books.

[30] Roth, Alvin E. and Marilda Sotomayor, [1989], "The College Admissions Problem Revisited", Econometrica, 57(3), 559-570.

[31] Schmidt, Klaus M. [1997]: "Managerial Incentives and Product Market Competition", Review of Economic Studies, 64, 191-213.

[32] Seabright, Paul, [2002], "Blood, Bribes and the Crowding-Out of Altruism by Financial Incentives," unpublished typescript, University of Toulouse.

[33] Sheehan, R. [1996]: "Mission Accomplishment as Philanthropic Effectiveness: Key Findings from the Excellence in Philanthropy Project," Non-profit and Voluntary Sector Quarterly, 25(1), 110-123.

[34] Tirole, Jean, [1994], "The Internal Organization of Government," Oxford Economic Papers, 46(1), 1-29

[35] Titmuss, Richard, [1970], The Gift Relationship, London: Allen and Unwin.

[36] Weisbrod, Burton A., [1988], The Nonprofit Economy, Cambridge MA, Harvard University Press. 
[37] Wilson, James Q., [1989], Bureaucracy: What Government Agencies Do and Why They Do It, New York: Basic Books.

\section{Appendix A: Proofs}

To prove Proposition 1, we proceed by proving two useful Lemmas. Assume a given value of $x$ and define $\bar{\alpha}_{j k}=\max \left\{\alpha_{j}, \alpha_{k}\right\}$ and $\underline{\alpha}_{j k} \equiv \min \left\{\alpha_{j}, \alpha_{k}\right\}$. Assumption 2 guarantees that $\theta_{j k}^{a}(x)>0$ and $\theta_{k j}^{p}(x)>0$ for all $x \in\left[\underline{\alpha}_{j k}, \bar{\alpha}_{j k}\right]$. Let $\Delta_{j k}=\Delta\left(p_{k}, a_{j}\right)$. Substituting for $e$ using the $I C C$, we can rewrite the optimal contracting problem in section 3.1 as:

$$
\max _{\{b, w\}} v_{k}^{p}=\left(b+\theta_{j k}^{a}(x)\right)\left(\theta_{k j}^{p}(x)-b\right)-w
$$

subject to:

$$
\begin{aligned}
w & \geq \underline{w} \\
v_{j}^{a} & =\frac{1}{2}\left(b+\theta_{j k}^{a}(x)\right)^{2}+w \geq \underline{u}\left(a_{j}\right) .
\end{aligned}
$$

This modified optimization problem involves two choice variables, $b$ and $w$, and two constraints, the $L L C$ and the $P C$. The objective function $v_{k}^{p}$ is concave and the constraints are convex. Now we are ready to prove:

Lemma 1: Under an optimal incentive contract at least one of the participation and the limited liability constraints will bind.

Proof: Suppose both constraints do not bind. As the $P C$ does not bind, the principal can simply maximize his payoff with respect to $b$ which yields

$$
b=\max \left\{\frac{\theta_{k j}^{p}(x)-\theta_{j k}^{a}(x)}{2}, 0\right\}
$$

and the corresponding effort level would be

$$
e=\left(b+\theta_{j k}^{a}(x)\right)=\max \left\{\frac{\theta_{k j}^{p}(x)+\theta_{j k}^{a}(x)}{2}, \theta_{j k}^{a}(x)\right\} .
$$

Since the PC is not binding, and by assumption $w>\underline{w}$, the principal can reduce $w$ by a small amount without violating any of these two constraints. This will not affect $e$, and yet increase 
his profits. This is a contradiction and so the principal will reduce $w$ until either the $L L C$ or the $P C$ binds. QED

Lemma 2: Under an optimal incentive contract, if the limited liability constraint does not bind, then $e$ is at the first-best level.

Proof: We prove the equivalent statement: "If $e$ is not at the first-best level then the limited liability constraint must bind". As $b \leq \theta_{k j}^{p}(x)$, effort cannot exceed the first-best level. The remaining possibility is that $e$ is less than the first-best level. Suppose this is the case, i.e., $e=b+\theta_{j k}^{a}(x)<\theta_{k j}^{p}(x)+\theta_{j k}^{a}(x)$. We claim that in this case the $L L C$ must bind. Suppose not. That is, we have an optimal contract $\left(b_{0}, l_{0}\right)$ such that $b_{0}<\theta_{k j}^{p}(x)$ and $w_{0}>\underline{w}$. Suppose we reduce $w_{0}$ by $\varepsilon$ and increase $b_{0}$ by an amount such that the agent's expected payoff is unchanged. Since the agent chooses effort to maximize his own payoff we can use the envelope theorem to ignore the effects of changes in $w$ and $b$ on his payoff via $e$. Then $d v_{j}^{a}=e d b+d w=0$. The effect of these changes on principal's payoff is $d v_{k}^{p}=d e\left(\theta_{k j}^{p}(x)-b\right)-(e d b+d w)$. The second term is zero by construction and the first term is positive and so the principal is better of. This is a contradiction. QED

Proof of Proposition 1: Now we are ready to characterize the optimal contract and prove existence. There are three relevant cases:

Case 1: The $P C$ does not bind and the agent is more motivated than the principal. We have already established in the proof of Lemma 1 that in this case the $L L C$ will bind and that:

$$
\begin{aligned}
b & =\max \left\{\frac{\theta_{k j}^{p}(x)-\theta_{j k}^{a}(x)}{2}, 0\right\}=0 \\
w & =\underline{w} \\
e & =b+\theta_{j k}^{a}(x)=\theta_{j k}^{a}(x) .
\end{aligned}
$$

The agent's payoff is

$$
\frac{1}{2}\left(b+\theta_{j k}^{a}(x)\right)^{2}+\underline{w}=\frac{1}{2}\left(\theta_{j k}^{a}(x)\right)^{2}+\underline{w} .
$$

Since the $P C$ does not bind by assumption in this case, the following must be true:

$$
\frac{1}{2} \theta_{j k}^{a}(x)^{2}>\underline{u}\left(a_{j}\right)-\underline{w} .
$$


The principal's payoff is

$$
\left(b+\theta_{j k}^{a}(x)\right)\left(\theta_{k j}^{p}(x)-b\right)-\underline{w}=\theta_{j k}^{a}(x) \theta_{k j}^{p}(x)-\underline{w} .
$$

Case 2: The $P C$ does not bind and the principal is more motivated than the agent. In this case:

$$
\begin{aligned}
b & =\max \left\{\frac{\theta_{k j}^{p}(x)-\theta_{j k}^{a}(x)}{2}, 0\right\}=\frac{\theta_{k j}^{p}(x)-\theta_{j k}^{a}(x)}{2} \\
w & =\underline{w} \\
e & =b+\theta_{j k}^{a}(x)=\frac{\theta_{k j}^{p}(x)+\theta_{j k}^{a}(x)}{2}
\end{aligned}
$$

The agent's payoff is

$$
\frac{1}{2}\left(b+\theta_{j k}^{a}(x)\right)^{2}+\underline{w}=\frac{1}{8}\left(\theta_{k j}^{p}(x)+\theta_{j k}^{a}(x)\right)^{2}+\underline{w} .
$$

Since the $P C$ does not bind by assumption in this case, the following must be true:

$$
\frac{1}{8}\left(\theta_{k j}^{p}\left(a_{j}, x\right)+\theta_{j k}^{a}(x)\right)^{2}>\underline{u}\left(a_{j}\right)-\underline{w} .
$$

The principal's payoff is

$$
\left(b+\theta_{j k}^{a}(x)\right)\left(\theta_{k j}^{p}(x)-b\right)-\underline{w}=\frac{1}{4}\left(\theta_{k j}^{p}(x)+\theta_{j k}^{a}(x)\right)^{2}-\underline{w} .
$$

Case 3: The $P C$ and the $L L C$ binds. These constraints then uniquely pin down the two choice variables for the principal. In particular, we get

$$
\begin{aligned}
w & =\underline{w} \\
b & =\sqrt{2\left(\underline{u}\left(a_{j}\right)-\underline{w}\right)}-\theta_{j k}^{a}(x)
\end{aligned}
$$

using which and the $I C C$ we get

$$
e=b+\theta_{j k}^{a}(x)=\sqrt{2\left(\underline{u}\left(a_{j}\right)-\underline{w}\right)} .
$$

As $b \leq \theta_{k j}^{p}(x), e=\sqrt{2\left(\underline{u}\left(a_{j}\right)-\underline{w}\right)} \leq \theta_{k j}^{p}(x)+\theta_{j k}^{a}(x)$. Therefore, $\underline{u}\left(a_{j}\right)-\underline{w} \leq \frac{1}{2}\left(\theta_{k j}^{p}(x)+\theta_{j k}^{a}(x)\right)^{2}$.

Notice that in this case $b>0$ as that is equivalent to $\left(\underline{u}\left(a_{j}\right)-\underline{w}\right)>\frac{1}{2}\left(\theta_{j k}^{a}(x)\right)^{2}$ and this must be true because otherwise the $P C$ would not bind and we would be in the previous case. The payoff of the agent in this case is by assumption,

$$
v_{j}^{a}=\underline{u}\left(a_{j}\right) .
$$


The principal's payoff is

$$
v_{k}^{p}=\sqrt{2\left(\underline{u}\left(a_{j}\right)-\underline{w}\right)}\left(\theta_{k j}^{p}(x)+\theta_{j k}^{a}(x)-\sqrt{2\left(\underline{u}\left(a_{j}\right)-\underline{w}\right)}\right)-\underline{w} .
$$

Since by assumption $\underline{u}\left(a_{j}\right) \leq \bar{v}_{j k}^{a}, v_{k}^{p} \geq 0$.

The other remaining possibility is that the PC binds but the LLC does not bind. By Lemma 2 we know that in this case $w \geq \underline{w}, b=\theta_{k j}^{p}(x)$ and $e=\theta_{j k}^{a}(x)+\theta_{k j}^{p}(x)$ which is the first-best level. From the $P C$ of the agent, $v_{j}^{a}=\frac{1}{2}\left(\theta_{k j}^{p}(x)+\theta_{j k}^{a}(x)\right)^{2}+w=\underline{u}\left(a_{j}\right)$. In this case the principal's payoff is $v_{k}^{p}=-w$ and so it is ruled out by the assumption that contracts are feasible, and must ensure a non-negative payoff for the principal.

We now characterize the optimal choice of $x$. To economize on notation, let $\theta_{p}(x)=\theta_{k j}^{p}(x)$, $\theta_{a}(x)=\theta_{j k}^{a}(x)$ for this section. Also, the first and second derivatives of these functions with respect to $x$ are denoted by $\theta_{l}^{\prime}(x)$ and $\theta_{l}^{\prime \prime}(x)$ with $l=p, a$. Let $\hat{\theta}(x)=\max \left\{\theta_{a}(x), \theta_{p}(x)\right\}+$ $\theta_{a}(x)$. From the above analysis, the principal's payoff under the optimal contract is:

$$
v_{k}^{p}=\left\{\begin{array}{ccc}
\theta_{a}(x) \theta_{p}(x)-\underline{w} & \text { for } \theta_{p}(x)<\theta_{a}(x) & \text { and } \underline{u}\left(a_{j}\right)-\underline{w}<\frac{1}{8}\{\hat{\theta}(x)\}^{2} \\
\frac{\left(\theta_{a}(x)+\theta_{p}(x)\right)^{2}}{4}-\underline{w}, & \text { for } \theta_{p}(x) \geq \theta_{a}(x) & \text { and } \underline{u}\left(a_{j}\right)-\underline{w}<\frac{1}{8}\{\hat{\theta}(x)\}^{2} \\
\sqrt{2\left(\underline{u}\left(a_{j}\right)-\underline{w}\right)}\left(\left(\theta_{a}(x)+\theta_{p}(x)\right)\right. & \text { for } & \frac{1}{8}\{\hat{\theta}(x)\}^{2} \leq \underline{u}\left(a_{j}\right)-\underline{w} \leq \bar{v}_{j k}^{a} . \\
-\sqrt{2\left(\underline{u}\left(a_{j}\right)-\underline{w}\right)}-\underline{w}, & &
\end{array}\right.
$$

Observe that a value of $x$ that exceeds $\alpha_{0}$ or is less than $\alpha_{1}$ will never be chosen since it is dominated by choosing $x=\alpha_{k}$ or $x=\alpha_{j}$. First consider choosing $x$ to maximize $\theta_{a}(x) \theta_{p}(x)$ subject to the constraint $\theta_{a}(x) \geq \theta_{p}(x)$. Note that $\theta_{p}^{\prime}(x)=-\omega_{p}\left(x-\alpha_{k}\right)$ and $\theta_{a}^{\prime}(x)=-\omega_{a}\left(x-\alpha_{j}\right)$ and, $\theta_{p}^{\prime \prime}(x)=-\omega_{p}$ and $\theta_{a}^{\prime \prime}(x)=-\omega_{a}$. The first derivative of $\theta_{a}(x) \theta_{p}(x)$ is $\theta_{a}(x) \theta_{p}^{\prime}(x)+\theta_{a}^{\prime}(x) \theta_{p}(x)$ and the second derivative is $\left(\theta_{a}^{\prime \prime}(x) \theta_{p}(x)+\theta_{p}^{\prime \prime}(x) \theta_{a}(x)\right)+2 \theta_{a}^{\prime}(x) \theta_{p}^{\prime}(x)$. Clearly the term within parentheses is negative. The second term is equal to $2 \omega_{a} \omega_{p}(x-$ $\left.\alpha_{k}\right)\left(x-\alpha_{j}\right)$ which is negative for $x \in\left[\underline{\alpha}_{j k}, \bar{\alpha}_{j k}\right]$. Therefore $\theta_{a}(x) \theta_{p}(x)$ is globally concave and the first-order condition characterizes the global maxima. The first-order condition is, upon simplification,

$$
2 x-\left(\alpha_{j}+\alpha_{k}\right)=\frac{1}{2}\left(x-\alpha_{j}\right)\left(x-\alpha_{k}\right)\left\{2 x-\left(\alpha_{j}+\alpha_{k}\right)\right\} .
$$

One root can be solved upon inspection, namely $x_{0}=\frac{\alpha_{j}+\alpha_{k}}{2}$. It is easy to see that if $x \neq \frac{\alpha_{j}+\alpha_{k}}{2}$ then the other two roots are solutions to $\frac{1}{2}\left(x-\alpha_{j}\right)\left(x-\alpha_{k}\right)=1$. But it can be readily verified that real-valued roots of this equation must lie outside the interval $\left[\underline{\alpha}_{j k}, \bar{\alpha}_{j k}\right]$ and so can be 
ignored. Let $\underline{\alpha}_{j k}=\alpha_{j}$ and $\bar{\alpha}_{j k}=\alpha_{k}$ without loss of generality. Evaluated at $x_{0}=\frac{\alpha_{j}+\alpha_{k}}{2}$, $\theta_{a}=\omega_{a}\left(1-\frac{1}{8} \triangle_{j k}^{2}\right)$ and $\theta_{p}=\omega_{p}\left(1-\frac{1}{8} \triangle_{j k}^{2}\right)$. As $\theta_{a}>\theta_{p}$ for $\omega_{a}>\omega_{p}$, the constraint $\theta_{a} \geq \theta_{p}$ does not bind and this concludes the proof of the first-part of the claim.

Next consider choosing $x$ to maximize $\frac{1}{4}\left(\theta_{a}(x)+\theta_{p}(x)\right)^{2}-w$ subject to the constraint $\theta_{p}(x) \geq \theta_{a}(x)$. Notice that $\theta_{a}(x)+\theta_{p}(x)$ is a concave function and that attains its global maximum at $x_{1}=\delta_{a} \alpha_{j}+\left(1-\delta_{a}\right) \alpha_{k}$ where $\delta_{a} \equiv \frac{\omega_{a}}{\omega_{a}+\omega_{p}}$. The first derivative of $\left(\theta_{a}(x)+\theta_{p}(x)\right)^{2}$ is $2\left(\theta_{a}(x)+\theta_{p}(x)\right)\left(\theta_{a}^{\prime}(x)+\theta_{p}^{\prime}(x)\right)=-2\left(\theta_{a}+\theta_{p}\right)\left\{\omega_{p}\left(x-\alpha_{k}\right)+\omega_{a}\left(x-\alpha_{j}\right)\right\}$. The unique critical point of $\frac{1}{4}\left(\theta_{a}(x)+\theta_{p}(x)\right)^{2}-w$ is therefore $x_{1}$. Once again, let $\underline{\alpha}_{j k}=\alpha_{j}$ and $\bar{\alpha}_{j k}=\alpha_{k}$ without loss of generality. Notice that the derivative is strictly positive for all $x \in\left[\alpha_{j}, x_{1}\right)$ and strictly negative for all $x \in\left(x_{1}, \alpha_{k}\right]$. Therefore, the function $\left(\theta_{a}(x)+\theta_{p}(x)\right)^{2}$ and affine transformations of it are pseudo-concave, and so the function attains a global maximum at $x=$ $x_{1}$ (see Simon and Blume, 1994, p. 527-28). Evaluated at $x_{1}, \theta_{a}=\omega_{a}\left\{1-\frac{1}{2}\left(1-\delta_{a}\right)^{2} \triangle_{j k}^{2}\right\}$ and $\theta_{p}=\omega_{p}\left\{1-\frac{1}{2} \delta_{a}{ }^{2} \triangle_{j k}^{2}\right\}$. If $\omega_{p}>\omega_{a}, 1-\delta_{a}>\delta_{a}$ and so $\theta_{p}>\theta_{a}$ at the optimum. If $\omega_{a}=\omega_{p}=\omega, x_{0}=x_{1}$ and so $\theta_{a}=\theta_{p}=\omega\left(1-\frac{1}{8} \triangle_{j k}^{2}\right)$ at the optimum. Finally, if the principal maximizes $\sqrt{2\left(\underline{u}\left(a_{j}\right)-\underline{w}\right)}\left(\left(\theta_{a}(x)+\theta_{p}(x)\right)-\sqrt{2\left(\underline{u}\left(a_{j}\right)-\underline{w}\right)}\right)-\underline{w}$, that is equivalent to maximizing $\theta_{a}(x)+\theta_{p}(x)$, which is a globally concave function with a unique maximum at $x_{1}$. This concludes the proof of the second part of the claim.

Finally, we must check that the optimal contract exists. The principal's expected payoff when $\underline{u}\left(a_{j}\right)=0$ is $\theta_{j k}^{a}(x) \theta_{k j}^{p}(x)-\underline{w}$. If $\omega_{a}>\omega_{p}$, substituting the expression for $x_{j k}^{*}$ we get $v_{k}^{p}=\omega_{a} \omega_{p}\left(1-\frac{1}{8} \triangle_{j k}^{2}\right)^{2}-\underline{w}$. By Assumption $1, \triangle_{j k}^{2}<2$ and so $v_{k}^{p}>0$ by Assumption 3 . Similarly, if $\omega_{a} \leq \omega_{p}, v_{k}^{p}=\frac{\left(\theta_{j k}^{a}\left(x_{j k}^{*}\right)+\theta_{k j}^{p}(x)\right)^{2}}{4}-\underline{w}=\frac{1}{4}\left(\omega_{a}+\omega_{p}\right)^{2}\left[1-\frac{1}{2} \frac{\omega_{a} \omega_{p}}{\left(\omega_{a}+\omega_{p}\right)^{2}} \triangle_{j k}^{2}\right]^{2}-\underline{w}$. As $\frac{1}{4}\left(\omega_{a}+\omega_{p}\right)^{2} \geq \omega_{a} \omega_{p}$ for all real values of $\omega_{a}$ and $\omega_{p}$ (with the equality holding only when $\left.\omega_{a}=\omega_{p}\right)$, and by Assumption 1, $\triangle_{j k}^{2}<2, v_{k}^{p}>\frac{1}{4}\left(\omega_{a}+\omega_{p}\right)^{2}\left(\frac{3}{4}\right)^{2}-\underline{w}$ which in turn is positive by Assumption 3. In both the cases above the agent receives a strictly positive payoff $\frac{1}{8}\left\{\hat{\theta}_{j k}\left(x_{j k}^{*}\right)\right\}^{2}+\underline{w}$ even though $\underline{u}\left(a_{j}\right)=0$. On the other extreme, if the principal's expected payoff is set to zero, the agent's expected payoff under the optimal contract is $\frac{1}{2}\left(e_{j k}^{*}\right)^{2}+\underline{w}$ where $e_{j k}^{*}=\frac{\theta_{j k}^{a}\left(x_{j k}^{*}\right)+\theta_{k j}^{p}(x)+\sqrt{\theta_{j k}^{a}\left(x_{j k}^{*}\right)+\theta_{k j}^{p}(x)-4 \underline{w}}}{2} \cdot{ }^{29}$ The agent's payoff $\bar{v}_{j k}^{a}$ is a strictly positive real number if $\left(\theta_{j k}^{a}\left(x_{j k}^{*}\right)+\theta_{k j}^{p}(x)\right)^{2}>4 \underline{w}$ which is indeed the case given Assumption 3 as argued above. For $\underline{u}\left(a_{j}\right) \geq \frac{1}{8}\left\{\hat{\theta}_{j k}\left(x_{j k}^{*}\right)\right\}^{2}+\underline{w}$, the $P C$ binds and the principal's payoff

${ }^{29}$ There is a second smaller root which is ignored using the Pareto-criterion. 
is a continuous and decreasing function of $\underline{u}\left(a_{j}\right)$, and so an optimal contract exists for all $\underline{u}\left(a_{j}\right) \leq \bar{v}_{j k}^{a} \cdot \mathrm{QED}$.

Proof of Corollary 1: In this case, $\theta_{M+1 j}^{p}=\pi>\theta_{j M+1}^{a}=0$ for all $j=1,2, . ., M+1$. As a result Proposition 1 can be readily modified to characterize the optimal contract in this case. The only concern is to ensure that the optimal contract exists. The principal's expected payoff when $\underline{u}\left(a_{j}\right)=0$ is $\frac{1}{4} \pi^{2}-\underline{w}$ and by Assumption 1 this is positive. Also, in this case the agent receives a payoff of $\frac{1}{8} \pi^{2}+\underline{w}$. Consider the case where the principal receives a zero expected payoff, i.e., $\sqrt{2\left(\underline{u}\left(a_{j}\right)-\underline{w}\right)}\left(\pi-\sqrt{2\left(\underline{u}\left(a_{j}\right)-\underline{w}\right)}\right)-\underline{w}=0$, or $\underline{u}\left(a_{j}\right)=\bar{v}_{j M+1}^{a}=$ $\frac{1}{8}\left(\pi+\sqrt{\pi^{2}-4 \underline{w}}\right)^{2}+\underline{w} \equiv \hat{u}$ which is a positive real number by Assumption 1 . Therefore by an argument similar to the one presented at the end of the proof of Proposition 1, an optimal contract exists for all $\underline{u}\left(a_{j}\right) \leq \bar{v}_{j M+1}^{a}$.QED.

Proof of Proposition 2: Let $\Gamma(\Delta)=\omega_{a}\left\{1-\frac{1}{2}\left(1-\delta_{a}\right)^{2} \triangle^{2}\right\}+\omega_{p}\left\{1-\frac{1}{2} \delta_{a}{ }^{2} \triangle^{2}\right\}$ and $\Lambda(\Delta)=\max \left\{\frac{\Gamma(\Delta)}{2}, \omega_{a}\left(1-\frac{1}{8} \triangle^{2}\right)\right\}$. Both of these are decreasing functions of $\Delta$. Define:

$S(\Delta, z)=\left\{\begin{array}{cll}\omega_{a} \omega_{p}\left(1-\frac{1}{8} \triangle^{2}\right)^{2}-\underline{w} & \text { for } \omega_{p}<\omega_{a} & \text { and } z-\underline{w}<\frac{1}{2}\{\Lambda(\Delta)\}^{2} \\ \frac{\{\Gamma(\Delta)\}^{2}}{4}-\underline{w}, & \text { for } \omega_{p} \geq \omega_{a} & \text { and } z-\underline{w}<\frac{1}{2}\{\Lambda(\Delta)\}^{2} \\ \sqrt{2(z-\underline{w})}(\Gamma(\Delta)-\sqrt{2(z-\underline{w})})-\underline{w}, & \text { for } & \frac{1}{2}\{\Lambda(\Delta)\}^{2} \leq z-\underline{w} \leq \bar{v}_{j k}^{a}\end{array}\right.$

to be the payoff of to a motivated principal when the congruence between his and his agent's preferences is $\Delta$ and the agent's reservation payoff is $z$. Observe that $S(\Delta, z)$ is (strictly) decreasing in $\Delta$ and (weakly) decreasing in $z$.

We now demonstrate that all stable matches must be assortative.

Step 1: $M=2$. Suppose that there is a stable non-assortative match with reservation payoffs $\left(z_{1}, z_{2}\right)$. Then stability implies principal one would not wish to bid away agent one. This boils down to:

$$
S\left(\Delta_{12}, z_{2}\right) \geq S\left(0, z_{1}\right) .
$$

But this implies that $z_{1}>z_{2}$ since $S\left(0, z_{2}\right)>S\left(\Delta_{12}, z_{2}\right)$. Similarly, the fact that principal two does not want to bid away agent two implies that:

$$
S\left(\Delta_{21}, z_{1}\right) \geq S\left(0, z_{2}\right) .
$$

But by a similar argument this implies that $z_{2}>z_{1}$, a contradiction. Therefore there is no stable non-assortative match where $M=2$. 
Step 2: We now prove that if it is true for $M=2$, then it is true for all $M>2$. Consider $M=3$. Since all outcomes in which two agents are not assortatively matched are unstable by the argument in Step 1, we need only check the case where all three types of principals and agents are not assortatively matched. Suppose for the sake of concreteness that $\mu(1)=3$, $\mu(2)=1$ and $\mu(3)=2$. Now we can use the argument above to show that $z_{1}>z_{3}, z_{2}>z_{1}$ and $z_{3}>z_{2}$. But summing these inequalities yields:

$$
z_{1}+z_{2}+z_{3}>z_{1}+z_{2}+z_{3}
$$

which is a contradiction.

Consider now the case for $M>3$. Suppose that it is true for $M-1$ and below. Then, we need only check the case where there is complete non-assortative matching for principals $j=1, . ., M$ and agents $i=1, \ldots, M$. But an argument analogous to that used for $M=2$, implies that for all principals $\ell$ and agent's $k$ who are matched:

$$
z_{k}<z_{\ell}
$$

Summing these inequalities yields $\sum_{i=1}^{M} z_{i}>\sum_{i=1}^{M} z_{i}$, a contradiction. Thus, if the outcome is unstable for $M-1$, then it is unstable for $M$. Hence, the fact that non-assortative matching is unstable for $M=2$, implies the result.QED.

Proof of Proposition 3: The stated contracts are optimal according to Proposition 1 and Corollary 1 relative to a common reservation payoff for all types of agents of:

$$
\hat{u}=\frac{1}{8}\left(\pi+\sqrt{\pi^{2}-4 \underline{w}}\right)^{2}+\underline{w} .
$$

Since $n_{M+1}^{p}>n_{M+1}^{a}$, there are unemployed unmotivated principals. Therefore, all employed principals in the profit-oriented sector must be earning zero profits. They cannot attract away an unmotivated agent from another unmotivated principal without earning a negative profit. Hence the matching within the unmotivated sector is stable. An agent of type $a_{j}$ receives a payoff of $v_{j}^{a}=\max \left\{\frac{1}{8}\left(\hat{\omega}+\omega_{a}\right)^{2}+\underline{w}, \hat{u}\right\} \equiv \hat{v}^{a}$ for $j=1,2, . ., M$. Given that all motivated agents earn $\hat{v}^{a}$ and $S\left(0, \hat{v}^{a}\right)>S\left(\Delta, \hat{v}^{a}\right)$ for all $\Delta>0$, matching is stable within the motivated sector. Finally, we show that matching between the profit-oriented and missionoriented sectors is stable. Let $g\left(x_{1}, x_{2}\right) \equiv \sqrt{2\left(x_{1}-\underline{w}\right)}\left(x_{2}-\sqrt{2\left(x_{1}-\underline{w}\right)}\right)-\underline{w}$. We check if a principal of type $p_{M+1}$ can offer him the same payoff or more, and still be strictly better 
off than he is in the proposed matched with an unmotivated agent. As $\frac{1}{8}\left(\hat{\omega}+\omega_{a}\right)^{2}+\underline{w} \geq$ $\frac{1}{8} \pi^{2}+\underline{w}$ (by Assumption 4), the $P C$ facing the principal of type $p_{M+1}$ will bind. Suppose $v_{j}^{a}=\frac{1}{8}\left(\hat{\omega}+\omega_{a}\right)^{2}+\underline{w}>\hat{u}$. Then the maximum payoff that a principal of type $p_{M+1}$ can earn from an agent of type $a_{j}$ is $g\left(v_{j}^{a}, \pi\right)<g(\hat{u}, \pi)$ as $v_{j}^{a}>\hat{u}$ in this case. But by construction $g(\hat{u}, \pi)=0$ in the full-employment case and so such a move is not attractive. Similarly, if $v_{j}^{a}=\hat{u}$, the maximum payoff that a principal of type $p_{M+1}$ can earn from an agent of type $a_{j}$ is $g(\underline{u}, \pi)$ which is the same that he earns in his current match. Next we show that a principal of type $p_{k}$ with $k=1,2, . ., M$ will not find it profitable to attract an unmotivated agent who earns $\hat{u}$. A principal of type $p_{k}$ can choose his own favorite mission when matched with an unmotivated agent. So the most he can earn is $g\left(\hat{u}, \omega_{p}\right)$ which is strictly less than $g\left(\hat{u}, \omega_{p}+\omega_{a}\right)$ which is what he was earning before, in case the $P C$ was binding. Notice that $g\left(\hat{u}, \omega_{p}\right)=\frac{1}{2}\left(\pi+\sqrt{\pi^{2}-4 \underline{w}}\right)\left\{\omega_{p}-\frac{1}{2}\left(\pi+\sqrt{\pi^{2}-4 \underline{w}}\right)\right\}-\underline{w} \leq \frac{1}{4} \omega_{p}^{2}-\underline{w}$ (since the expression $y(a-y)$ is maximized at $\left.y=\frac{a}{2}\right)$. If the $P C$ was not binding then the principal was earning either $\omega_{a} \omega_{p}-\underline{w}$ (if $\omega_{a}>\omega_{p}$ ) or $\frac{\left(\omega_{p}+\omega_{a}\right)^{2}}{4}-\underline{w}$ (if $\omega_{a} \leq \omega_{p}$ ). In the former case, as $\omega_{a}>\omega_{p}$, $\omega_{a} \omega_{p}-\underline{w}>\frac{1}{4} \omega_{p}^{2}-\underline{w}$. In the latter case, $\frac{1}{4} \omega_{p}^{2}-\underline{w} \leq \frac{\left(\omega_{p}+\omega_{a}\right)^{2}}{4}-\underline{w}$ for all $\omega_{a} \geq 0, \omega_{p}>0$. Thus, the proposed matching is stable as claimed. QED.

Proof of Proposition 4: The stated contracts are optimal contract according to Proposition 1 and Corollary 1 relative to a common reservation payoff of zero. This is what we would expect as $n_{M+1}^{p}<n_{M+1}^{a}$ and so there are unemployed agents. The rest of the proof is similar to that of Proposition 3, and is hence omitted. QED 


\section{Appendix B: Sorting on Motivation}

Suppose now that every principal and agent has the same mission preferences. i.e. $\Delta\left(p_{k}, a_{j}\right)=$ 0 . However, there are differences in the extent of motivation. Thus:

$$
\theta_{k j}^{p}(x)=\omega_{k p} \text { for all } a_{j} \in \mathcal{A}_{a} \text { with } \omega_{1 p}>\ldots>\omega_{M p}>\omega_{M+1 p}=\pi
$$

and

$$
\theta_{j k}^{a}(x)=\left\{\begin{array}{cc}
\omega_{j a} & \text { for all } k \leq M \text { with } \omega_{1 a}>\ldots>\omega_{M a} \\
0 & \text { if } k=M+1 \text { or } j=M+1 .
\end{array}\right.
$$

For simplicity we focus on the case where:

$$
\omega_{k a}=\omega_{k p}=\omega_{k}
$$

Assume also that $2 \omega_{M}<\pi$.

Let $Y=\max \left\{\frac{x+y}{2}, y\right\}$. Then define

$$
S(x, y, z)=\left\{\begin{array}{cll}
x y-\underline{w} & \text { for } \omega_{p}<\omega_{a} & \text { and } z-\underline{w}<\frac{1}{2}\{Y\}^{2} \\
\frac{(x+y)^{2}}{4}-\underline{w}, & \text { for } \omega_{p} \geq \omega_{a} & \text { and } z-\underline{w}<\frac{1}{2}\{Y\}^{2} \\
\sqrt{2(z-\underline{w})}(x+y-\sqrt{2(z-\underline{w})})-\underline{w}, & \text { for } & \frac{1}{2}\{Y\}^{2} \leq z-\underline{w} \leq \bar{v}_{j k}^{a}
\end{array}\right.
$$

as the surplus of a principal whose motivation is $x$ when he employs an agent whose motivation is $y$ at reservation utility $z$. Observe that $S(x, y, z)$ is increasing in $x$ and $y, S_{12} \geq 0$ and $S_{13} \geq 0$ for all types $x, y$ and reservation utility $z$. Therefore, it satisfies the differentiable version of the generalized increasing differences condition of Legros and Newman (2003, Proposition 2) and so we know that there will be positive assortative matching in this case. ${ }^{30}$

We now construct a set of contracts which achieve this assortative matching in one special case. Suppose that $n_{K+1}^{a}<n_{K+1}^{p}$ (full employment). Then the following set of contracts support the stable positive assortative matching:

\footnotetext{
${ }^{30}$ We cannot apply the results of Legros and Newman (2003) for our earlier analysis of sorting on missionpreferences because there the sorting is "horizontal" as opposed to "vertical", as in the present case. In particular, here all principals would prefer to have an agent with higher motivation, and the greater their own motivation, the more they value a high motivation agent. In the earlier case it is not always the case that a higher type principal has a higher relative valuation of a higher type agent. Suppose $\alpha_{1}>\alpha_{2} . .>\alpha_{M}$. Then, for example, if the two principals are types $p_{1}$ and $p_{2}$ and the two agents are types $a_{2}$ and $a_{3}$, then the generalized increasing differences condition could fail.
} 
(i) $w^{*}\left(\mu\left(a_{j}\right), a_{j}\right)=\underline{w}$ for all $j=1, \ldots, M+1$

(ii) The bonus payment in the mission-oriented sector is:

$$
b^{*}\left(\mu\left(a_{j}\right), a_{j}\right)=\max \left\{\frac{\omega_{j-1}-\omega_{j}+\sqrt{\left(\omega_{j-1}+\omega_{j}\right)^{2}-4 \underline{w}}}{2}, 0\right\}
$$

for all $j=1, \ldots, M-1$ and

$$
b^{*}\left(\mu\left(a_{M}\right), a_{M}\right)=\max \left\{\frac{\pi+\sqrt{\pi^{2}-4 \underline{w}}}{2}-\omega_{M}, 0\right\}
$$

(iii) The bonus payment in the profit oriented sector is:

$$
b^{*}\left(\mu\left(a_{M+1}\right), a_{M+1}\right)=\frac{\pi+\sqrt{\pi^{2}-4 \underline{w}}}{2} .
$$

It is easy to check that these are optimal contracts in the sense of Proposition 1 . The reservation payoffs are:

$$
\begin{aligned}
u_{j} & =\frac{1}{2}\left(\frac{\omega_{j}+\omega_{j+1}+\sqrt{\left(\omega_{j}+\omega_{j+1}\right)^{2}-4 \underline{w}}}{2}\right)^{2}+\underline{w} \text { for } j=1, \ldots, M-1 \\
u_{M} & =\frac{1}{2}\left(\frac{\pi+\sqrt{\pi^{2}-4 \underline{w}}}{2}\right)^{2}+\underline{w} .
\end{aligned}
$$

In the present environment all principals would prefer to have an agent with higher motivation. Given that the generalized increasing differences condition is satisfied, stable allocations involve positive assortative matching on motivation. The above set of contracts support such an allocation because the reservation payoffs are such that a principal of type $\omega_{j}$ earns zero profits if he hires an agent of type $\omega_{j-1}$ (and negative profits if he hires an agent of type $\omega_{j-l}$ with $\left.l \geq 2\right)$ but positive profits if he hires an agent of the same type. In particular, $S\left(\omega_{1}, \omega_{1}, u_{1}\right)>0$, and for all $j=2, . ., M$ :

$$
0=S\left(\omega_{j}, \omega_{j-1}, u_{j-1}\right)<S\left(\omega_{j}, \omega_{j}, u_{j}\right)
$$

